\title{
Validation of GRACE-derived Terrestrial Water Storage from a regional approach over South America
}

\author{
Frédéric Frappart (1,2), Lucía Seoane (1), Guillaume Ramillien (1,2) \\ (1) Université de Toulouse, OMP-GET, UM5563, CNRS/IRD/UPS, 14 Avenue Edouard \\ Belin, 31400 Toulouse, France \\ (2) Groupe de Recherche en Géodésie Spatiale
}

Abstract : We propose to validate regional solutions consisting of $2^{\circ}$ surface tiles of surface mass concentration over South America $\left(90^{\circ} \mathrm{W}-30^{\circ} \mathrm{W} ; 60^{\circ} \mathrm{S}-20^{\circ} \mathrm{N}\right)$ computed using accurate Level-1 GRACE measurements, by confronting them to other GRACE products (i.e., global GRGS and ICA-400 km GFZ/CSR/JPL combined solutions) and independent in situ river level and discharge datasets. For this purpose, Principal Component Analysis (PCA) was applied to all these types of the GRACE-based solutions to extract the corresponding main orthogonal spatial and temporal modes of variability to be compared for 2003-2010. For the first three spatial modes, regional solutions provide a better geographical localization of hydrological structures, especially indicating major surface and groundwater systems of South America. Over hydrological patterns, records of river level versus time are particularly consistent with the GRACE temporal modes, especially for our regional solutions (i.e., correlations generally greater than 0.7). Interannual variations of GRACE-based Terrestrial Water Storage (TWS) clearly exhibit the signatures of extreme climatic events as the recent droughts and floods that affected South America. Very significant agreement is also found at interannual time-scale between TWS and discharges in drainage basins dominated by the surface reservoir (more than 0.9 of correlation in the Amazon basin).

Keywords : GRACE; surface water; groundwater, water levels; discharges 
28 Continental water storage is a key component of the global hydrological cycle which plays a 29 major role in the Earth's climate system that controls over water, energy and biogeochemical 30 fluxes. In spite of its importance, the total continental water storage is not well-known at regional 31 and global scales because of the disparity of in situ observations and systematic monitoring of the 32 terrestrial water reservoirs, especially the groundwater component (Alsdorf and Lettenmaier, 33 2003).

34 The Gravity Recovery and Climate Experiment (GRACE) mission provides a global mapping of

35 the time-variations of the gravity field at an unprecedented resolution of $\sim 400 \mathrm{~km}$ and a 36 centimetric precision in terms of geoid height. Tiny variations of gravity measured by GRACE 37 are mainly due to redistribution of mass inside the fluid envelops of the Earth (i.e., atmosphere, oceans and continental water storage) from monthly to decadal timescales (Tapley et al., 2004).

39 Since its launch in March 2002, the GRACE terrestrial water storage anomalies have been 40 increasingly used for large-scale hydrological applications (see Ramillien et al., 2008a; Schmidt 41 et al., 2008 for reviews). These studies demonstrated a great potential to monitor extreme 42 hydrological events (Andersen et al., 2005; Seitz et al., 2008; Chen et al., 2009; Frappart et al., in 43 press), to monitor aquifer storage (Rodell et al., 2007; Strassberg et al., 2007; Leblanc et al., 44 2009) and snowpack (Frappart et al., 2011a) variations, and to estimate hydrological fluxes, such 45 as basin-scale evapotranspiration rate (Rodell et al., 2004; Ramillien et al. , 2006) and discharge 46 (Syed et al., 2009).

47 Unfortunately, GRACE Level-2 solutions suffer from the presence of important north-south 48 striping when determining Stokes coefficients (i.e., spherical harmonics of the geopotential 
corrected from known gravitational accelerations using a priori models for atmosphere, ocean

50 mass, and tides) which are geophysically unrealistic, and aliasing of short-time phenomena.

51 Because of these effects of striping that limits further interpretation, different post-processing

52 approaches for filtering these residual GRACE geoid solutions have been proposed to extract

53 useful hydrological signals (see Ramillien et al., 2008a; Schmidt et al., 2008 for reviews) with the

54 risk of losing energy in the short wavelengths domain, and thus missing details (i.e., loss of

55 resolution).

56 To overcome this problem, local determination of the time variations of the surface water storage

57 has been developed (Rowlands et al., 2005; Eicker, 2008). They are of great interest for regions where very localized important mass variations occur, such as flood and glaciers fields. Mascons

59 consist of adjusting regional heights of individual surface elements by using scaling factors of

60 spherical harmonics. However, they remain equivalent to classical global solutions (Rowlands et

61 al., 2010). Another type of regional approach has been more recently proposed by directly 62 adjusting the surface mass density distribution at the surface of the Earth from the Level-1

63 GRACE data, especially the accurate satellite-to-satellite velocity variations or K-Band Range

64 Rate (KBRR) measurements (Ramillien et al., 2011), and taking spatial correlations versus the 65 geographical distance between juxtaposed surface elements into account (Ramillien et al., 2012).

66 In particular, power spectral density reveals that the regional solutions computed over South 67 America are more energetic than the bandlimited global Level-2 solutions at short and medium 68 spatial wavelengths $(<4,000 \mathrm{~km})$ (Ramillien et al., 2012). In the present study, our goal is to 69 demonstrate that the excess of energy present at short wavelengths (between 400 and $1000 \mathrm{~km}$ ) in 70 the regional solutions compared to the global solutions can be related to realistic geophysical 71 signals corresponding to hydrological events such as floods, melt of glaciers, or groundwater 72 variations. To verify this assumption, a Principal Component Analysis (PCA) was first applied to 
73 the GRACE-based regional and global solutions. The resulting spatial and temporal modes were

74 compared to spatial distribution of surface and ground waters and correlated to water levels

75 variations from in situ gauges located close to the mouth of the major river basins and sub-basins

76 of South America respectively. Then, basin-averaged anomalies of TWS from this regional

77 approach are compared with changes of in situ surface water discharges in the largest drainage

78 basins of South America (i.e., Amazon, La Plata, Orinoco, and Tocantins), as well as basin-

79 averaged anomalies of TWS from global GRACE solutions.

80 To our knowledge, there is no large area in the world covered with a sufficient density of in situ

81 measurements of all the hydrological reservoirs to directly validate GRACE data. Most of the

82 previous studies dealing with the validation of the data present comparisons between GRACE-

83 based TWS and hydrological outputs, and/or comparisons with external hydrological datasets

84 such as gridded rainfall and in situ water levels and discharges (see Ramillien et al., 2008a;

85 Schmidt et al., 2008 for reviews). Here, we have chosen to compare the GRACE-based TWS

86 from our regional approach to other global available solutions and to, according to your opinion,

87 a profound and extensive datasets of in situ water levels. We decided not to compare to

88 hydrological model outputs because most of the hydrological models do not simulate the slow

89 reservoirs such as the floodplains and the groundwater.

\section{Datasets \& Methods}

2.1 Water mass variations from GRACE solutions

96 An alternative regional approach to the ones based on spherical harmonics has been recently

97 proposed to improve geographical localization of hydrological structures and to reduce leakage 
and aliasing errors. Our regional approach consists of determining water mass variations over juxtaposed surface elements in a given continental region from GRACE residuals potential differences anomalies, in terms of equivalent-water heights. According to the energy integral approach, these latter along-track anomalies correspond mainly to the contribution of the continental hydrology to the gravity field changes measured by GRACE, they are obtained from KBR range velocities differences between the two GRACE satellites after a priori (i.e., de-aliasing) corrections of mass variations ocurring in the oceans and the atmosphere, are made by pre-processing of GRACE observations. By assuming the conservation of energy along the GRACE groundtracks, it consists of recovering equivalent-water thicknesses of juxtaposed 2 by 2-degree geographical tiles by inverting GRACE inter-satellite KBR Range (KBRR) residuals (see Ramillien et al.; 2011, 2012). These KBRR residuals were obtained by correcting the raw GRACE observations from the a priori gravitational accelerations of known large-scale mass variations (i.e., atmosphere and oceanic mass variations, polar movements, as well as solid and oceanic tides) during the iterative least-squares orbit adjustment made using the GRGS GINS software (Lemoine et al., 2007; Bruinsma et al., 2010). The effects of nonconservative forces measured by on-board GRACE accelerometers are also removed from the 113 along-track observations, in order to extract the contributions of the remaining not modelled 114 phenomena, thus mainly water mass changes in continental hydrology. Since classical 115 gravimetric inversion does not provide a unique solution and to reduce the spurious effects of the noise in the observations, regularization strategies have been proposed to find numerically stable 117 regional solutions, either based on Singular Value Decomposition (SVD) and L-curve analysis 118 (Ramillien et al., 2011), or by introducing spatial constraints (Ramillien et al., 2012). Time series 119 of successive 10-day regional solutions of water mass have been produced over the whole South 120 America $\left(90^{\circ} \mathrm{W}-30^{\circ} \mathrm{W} ; 60^{\circ} \mathrm{S}-20^{\circ} \mathrm{N}\right)$ following this regional approach for $2002-2010$, and these 121 $2^{\circ}$-by- $2^{\circ}$ maps revealed realistic amplitudes, for spatial wavelengths lesser than the dimensions of 
122 the region itself by construction (i.e., $<6500-8000 \mathrm{~km}$, or equivalently harmonic degrees less

123 than 5-6 for South America). Numerical estimations show us that the predicted regional solutions

124 need to be completed by long wavelength components before being compared with other data

125 sets, when the geographical region is not large enough to contain these long gravity undulations.

126 Over South America, we complemented each regional solution with short and medium

127 wavelengths up to degree 5 from the corresponding GRGS solution (for more details see

128 Ramillien et al., 2012).

\subsubsection{ICA-filtered solutions}

130 A post-processing method based on Independent Component Analysis (ICA) was applied to the

131 Level-2 GRACE solutions from different official providers (i.e., UTCSR, JPL and GFZ), after 132 pre-filtering with 400-km-radius Gaussian filters. This approach does not require any a priori 133 information, except the assumption of statistical independence between the elementary sources 134 that compose the measured signals (i.e., useful geophysical signals plus noise). Separation 135 consists of finding the independent sources by solving a linear system relating the GRACE 136 solutions provided for a given month, to the unknown independent components. The contributors 137 to the observed gravity field are forced to be uncorrelated numerically by imposing diagonal 138 cross-correlation matrices. For a given month, the ICA-filtered solutions only differ to each other 139 from a scaling factor, so that the GFZ-derived ICA-filtered solutions are only considered. The 140 efficiency of the ICA in separating gravity signals from noise by combining Level-2 GRACE 141 solutions has previously been demonstrated over land (Frappart et al. 2010, 2011b) and ice caps 142 (Bergmann et al., 2012). These monthly ICA solutions are available at: http://grgs.obs-mip.fr. 143 They correspond to what is referred to the first ICA mode (whereas the second and third mode 144 corresponds to the noise) in Frappart et al. (2011b). Time series of ICA-based global maps of 
145 continental water mass changes from combined UTCSR, JPL and GFZ GRACE solutions, 146 computed over the period 08/2002-12/2010, are used in this study. More details about the post147 processing can be found in Frappart et al. (2010, 2011b).

\subsubsection{GRGS solutions}

150 As for the global Level-2 solutions computed by official providers (CSR, GFZ, and JPL), The

151 Level-2 GRGS-EIGEN-GL04 models are derived from Level-1 GRACE measurements including 152 KBRR, and from LAGEOS-1/2 SLR data for enhancement of lower harmonic degrees (Lemoine 153 et al., 2007; Bruinsma et al., 2010). These gravity fields are expressed in terms of normalized 154 spherical harmonic coefficients of the geopotential (i.e., Stokes coefficients) from degree 2 up to 155 degree 50-60 using an empirical stabilization approach without any smoothing or filtering. This 156 stabilization approach consists in adding empirically-determined degree and order-dependent 157 coefficients to minimize the time variations of the signal measured by GRACE over ocean and 158 desert without significantly affecting the amplitude of the signal over continents. 10-day 159 (Release-2) Total Water Storage (TWS) grids of 1-degree spatial resolution available at 160 http://grgs.obs-mip.fr are used over 2003-2010.

$161 \quad 2.2$ In situ water levels and discharge

162 Time series of daily water levels from in situ gauges located in the largest drainage basins of 163 South America (Amazon, La Plata, Orinoco, Tocantins, São Francisco, Negro) and their 164 tributaries (Fig. 1 and Table 1) and monthly discharges in Obidos (Amazon), Ciudad Bolivar 165 (Orinoco), Tucurui (Tocantins), and Chapeton (La Plata) were used for comparisons to 10-day 166 and monthly anomalies of GRACE-based TWS over 2003-2010. These in situ records were 167 downloaded either from the Environmental Research Observatory (ORE) HYBAM website 
168 (http://www.ore-hybam.org/) for the Orinoco basin and some gauges located in the Amazon 169 basin, and from the hydrological information system Hidroweb (http://hidroweb.ana.gov.br/) of 170 the Brazilian water agency (Agência Nacional de Aguas - ANA) for some gauges located in the 171 Amazon and the Tocantins basins, as well as from the Argentinian water agency (Instituto 172 Nacional del Agua -INA) through the online database Base de Datos Hidrológica Integrada

173 (BDHI - http://www.hidricosargentina.gov.ar/) over the period 2002 - 2011. The seasonal 174 amplitude was removed using a 13-month sliding window on each time-serie of daily in situ 175 water levels and monthly discharge.

\subsection{Maps of water resources}

2.3.1 Floodplains, wetlands and lakes database

178 The Global Land and Wetlands Database (GLWD) based on the combination of different 179 available cartographic sources is a comprehensive database of global lakes with an area greater 180 than $1 \mathrm{~km}^{2}$ and provides a good representation of the maximum global wetland extent (Lehner 181 and Döll, 2004). We used the GLWD-3 product with a spatial resolution of 30' to locate the 182 surface waters (i.e., large-scale wetland distributions and important wetland complexes) over 183 South America.

\subsubsection{Groundwater resources map}

186 The Worldwide Hydrological Mapping and Assessment Programme (WHYMAP) made available 187 a 1:25,000,000 map of groundwater resources through the website of the German Federal 188 Institute for Geosciences and Natural Resources (Bundesanstalt für Geowissenschaften un 189 Rohstoffe - BGR): http://www.whymap.org. This map presents the geographical extent of the 190 aquifers and their environmental charcateristics: large and rather uniform groundwater basins, 191 complex hydrogeological structures, and limited groundwater resources in local and shallow 

193 model outputs (Döll and Fiedler, 2008).

$194 \quad 2.4$ Time-series of TWS expressed in terms of equivalent sea level at basin-scale

195 For a given month $t$, regional average of TWS expressed in terms of $\mathrm{mm}$ of equivalent-water 196 height $\left(\Delta h_{T W S}(t)\right)$ over a given river basin of area $S$ is computed from the TWS anomaly grid $197\left(\Delta h\left(\lambda_{j}, \varphi_{j}, t\right)\right)$ at time $t$ of the pixel of longitude and latitude $\left(\lambda_{j}, \varphi_{j}\right)$ with $j=1,2, \ldots$ inside $S$, and the 198 elementary surface $R_{e}^{2} \Delta \lambda \Delta \varphi \cos \varphi_{j}$ (Ramillien et al., 2005; Frappart et al., 2011a):

$$
\Delta h_{T W S}(t)=\frac{R_{e}^{2}}{S} \sum_{j \in S} \Delta h\left(\lambda_{j}, \varphi_{j}, t\right) \cos \left(\varphi_{j}\right) \Delta \lambda \Delta \varphi
$$

where $R_{e}$ is the mean radius of the Earth $(6378 \mathrm{~km})$ and $\Delta \lambda$ and $\Delta \varphi$ are the grid steps in longitude and latitude respectively (generally $\Delta \lambda=\Delta \varphi$ ).

202 The time-series of TWS expressed in EWH for the four largest South American drainage basins 203 are then converted into Equivalent Sea Level (ESL) $\left(\Delta h_{T W S_{-} E S L}(t)\right)($ Ramillien et al., 2008b):

$$
\Delta h_{T W S_{-} E S L}(t)=\frac{\rho_{S W} S_{\text {basin }}}{\rho_{\text {ocean }} S_{\text {ocean }}} \Delta h_{T W S}(t)
$$

where $\rho_{S W}$ and $\rho_{\text {ocean }}$ are the densities of soil water and ocean (with the respective values of 1,000 and $1,030 \mathrm{~kg} \cdot \mathrm{m}^{-3}$ ), and $S_{\text {basin }}$ and $S_{\text {ocean }}$ the surfaces of the considered basin and the global ocean $\left(S_{\text {ocean }}=360\right.$ millions of $\left.\mathrm{km}^{2}\right)$ respectively.

\section{Results}

212 A Principal Components Analysis (PCA) was applied to the series of GRACE-based TWS from 213 Regional, ICA, and GRGS solutions over South America $\left(-90^{\circ}--30^{\circ} ;-60^{\circ}-20^{\circ}\right)$ for the period 
214 2003-2010, after removal of the dominant seasonal amplitude using a 13-month sliding window.

215 The sum of the explained variances $\left(\sigma^{2}\right)$ of the four first PCA modes represents 0.87 for the 216 regional, 0.82 for the ICA-GFZ-400km (0.83 for both ICA-CSR-400km and ICA-JPL-400km), 217 and 0.92 for the GRGS solutions (Table 2). The explained variance by a mode corresponds to the 218 variance in the dataset explained by a PC, the sum of the variances or total variance equals $100 \%$.

219 Most of the seasonally corrected signal present in the GRACE-derived land water solutions is 220 mostly concentrated in these four modes that will be analyzed in detail in the following.

221 The resulting 4 first modes are respectively presented in Fig. 2, 4, 6, and 8 for the spatial 222 components and in Fig. 3, 5, 7, 9 for the temporal components. Spatial components of the 4 first 223 modes exhibit similar patterns for the different GRACE solutions. Correlations between pairs of 224 GRACE solutions for each spatial mode can be found in Table 3. They are generally higher 225 between regional and ICA solutions than between regional and GRGS solutions (i.e., $\mathrm{R}_{\text {(regional; ICA) }}$ $226-\mathrm{R}_{\text {(regional; GRGS) }}>0.23$ ), except for the fourth mode. The major difference between the regional 227 and the global solutions is the complete absence in the regional solutions of spurious meridional 228 undulations materialized as north-south stripes, and unfortunately polluting the spatial patterns of 229 the global ones. These north-south stripes appear as one the major features in the $1^{\text {st }}$ spatial mode 230 of the GRGS solutions (Fig. 2c), and can also be identified in the $2^{\text {nd }}$ spatial mode of the GRGS 231 (Fig. 4c), as well as in the $1^{\text {st }}$ and $4^{\text {th }}$ spatial modes of the ICA solutions (Fig. 2b and Fig. 8b 232 respectively) but with a lower intensity. The presence of these stripes account for the lower 233 agreement between the $1^{\text {st }}$ mode of GRGS and regional (but also ICA) solutions (Table 3). 234 Besides, for the $2^{\text {nd }}$ and $3^{\text {rd }}$ modes, this lower agreement results from the different geographical 235 locations of the extrema. 
236 The large negative pattern located above the Equator in the $2^{\text {nd }}$ mode of the regional and ICA 237 solutions (Fig. 4a and b respectively) is centered on the Equator in the $2^{\text {nd }}$ mode of the GRGS 238 solutions (Fig. 4c). The two maxima centered around $-70^{\circ}$ of longitude and $-5^{\circ}$ of latitude, and $23970^{\circ}$ of longitude and $-5^{\circ}$ of latitude (Fig. $4 \mathrm{a}$ and $\mathrm{b}$ respectively), in the $2^{\text {nd }}$ mode of the regional 240 and ICA solutions, are absent from the $2^{\text {nd }}$ mode of the GRGS solutions (Fig. 4c). Accordingly, 241 the maximum and minimum located on the right and left banks of the Amazon have a different 242 shape in the $3^{\text {rd }}$ mode of the regional and ICA solutions (Fig. 6a and b respectively), and in the $3^{\text {rd }}$ 243 mode of the GRGS solutions (Fig. 6c). This different behavior of the GRGS products compared 244 with other regional and global solutions has already been reported by Klees et al. (2008) over 245 different large continental areas and river basins, and lately by Awange et al. (2011) over 246 Australia. It was attributed to leakage effect (Klees et al., 2008) caused by the low cut-off degree 247 applied to GRGS solutions (i.e., $\mathrm{n}=50$ or spatial resolution of $400 \mathrm{~km}$ ) compared to the one 248 applied to other global solutions (i.e., $\mathrm{n}=60$ for CSR and $\mathrm{n}=120$ for GFZ and JPL, or spatial 249 resolutions of $333 \mathrm{~km}$ and $167 \mathrm{~km}$ respectively), and moreover to the north-south striping largely 250 affecting these global solutions (Awange et al., 2011). For the $4^{\text {th }}$ mode, the lower agreement 251 between regional and ICA solutions can be attributed to the smoothness of these solutions that are 252 twice filtered using a Gaussian filter of $400 \mathrm{~km}$ of radius before being separated by ICA.

253 Temporal components of the four $1^{\text {st }}$ modes of the PCA of the GRACE solutions also present 254 quite similar profiles. Cross-correlations between pairs of GRACE solutions for each temporal 255 mode were also computed for time-lag $(\Delta t)$ varying between \pm 6 months. Results are presented in 256 Table 4 for $\Delta t=0$ and $\Delta t$ maximizing the cross-correlation into the one-year window. Similarly to 257 what was earlier revealed for the spatial components, greater correlations are found between the 258 regional and the ICA solutions than between the regional and the GRGS solutions for smaller 
259 time-delays, except for the $4^{\text {th }}$ mode (Table 4). Similar large time-shifts between GRGS and other 260 types of GRACE solutions were already observed over Australia and attributed to the large 261 impact of degrading north-south striping on the restitution of the hydrological signals, especially 262 at interannual time-scales (Awange et al., 2011). South America is covered by large drainage basins where surface waters represent a large part of the TWS measured by GRACE (Frappart et al., 2008; 2011c; 2012; Han et al., 2009; Kim et al., 2009). So, the spatial and temporal components of the PCA of the GRACE-based TWS are respectively compared to the spatial distribution of lakes and reservoirs, rivers and associated 270 floodplains, and wetlands from GLWD (Lehner and Döll, 2004), and the interannual variations of 271 water levels at the mouth of the South America's major rivers and tributaries (see the location of 272 the selected in situ gauges in Fig. 1). We deliberately limited our analysis to the in situ gauges at 273 located at (or close to) the mouth of a (sub-)basin, to be representative of a sufficiently large 274 drainage area, to remain compatible with the spatial resolution of the GRACE-based hydrological 275 products (i.e., $300-400 \mathrm{~km})$.

276 The spatial component of the PCA first mode is presented in Fig. 2a-c for respectively regional $277\left(\sigma^{2}=0.43\right)$, ICA-CSR-400 km $\left(\sigma^{2}=0.44\right)$, noted ICA in the followings, and GRGS $\left(\sigma^{2}=0.6\right)$ land 278 water solutions. In spite of the coarse spatial resolution of the GRACE data, it agrees well with 279 the distribution of surface water from GLWD (Fig. 2d). The strongest amplitudes of the first mode are located in the Altiplano region, area of inland in the Central Andes encompassing 281 Titicaca and Poopó lakes, along the Solimões-Amazon corridor (including the south of the 282 Amazonian and the Negro basins), in the delta of La Plata, upstream the mouth of the Tocantins, 
and in the region covered with Pindare and Parnacaiba basins (Fig. 2d). Some secondary extrema 284 are also seen at the mouth of the Orinoco basin, the region of the sources of the Parana (La Plata) and São Francisco rivers, and in the Deseado basin in Patagonia and over Patagonia Icefield (Fig.

286 2d). These hydrological structures are better concentrated on the regional (Fig. 2a) than on the 287 global spherical harmonics solutions (Fig. 2b and c). One of the main advantages in considering 288 regional solutions is to concentrate the starting GRACE information in a chosen portion of the 289 terrestrial surface (i.e., better spatial localization), instead of dealing with global spectral 290 coefficients (i.e., best frequency localization) (see Freeden and Schreiner, 2008). In the latter 291 case, by construction, the satellite signals are diluated over all the terrestrial sphere, consequently 292 any sharp surface detail should be reconstructed by a quasi-infinite sum of spherical harmonic 293 coefficients, which remains impossible in practice as GRGS and ICA solutions are limited up to 294 degree 50-60. The associated temporal component for each GRACE solutions is presented in Fig. 295 3a. The three time-series appear very similar, however the GRGS one being smoother. The 296 regional and the ICA solutions exhibit larger negative peaks in 2005 and 2010, and positive in 2972009 , corresponding to the extreme droughts and flood which strongly affected the Amazon basin 298 (Chen et al., 2009; 2010a; Marengo et al., 2011; Tomasella et al., 2011; Frappart et al., 2012; in 299 press), and to the 2009 drought that affected La Plata Basin (Chen et al., 2010b; Pereira and 300 Pacino, 2012), than the GRGS solutions. Regional and ICA solutions are almost in phase except 301 for the 2009 extreme flood when the ICA peak is located in the beginning of the year whereas it 302 occurs later (April-May) in the regional solutions, close to the flood peak in the Amazon basin.

303 Comparisons to in situ gauges highly (anti)correlated to mode 1 are presented in Fig. $3 b$ and 304 Table 5. Please note that anti-correlations come from the arbitrary sign given to both the spatial 
and temporal components. In all cases, the anti-correlation corresponds to region where the 306 spatial mode has a negative sign.

307 Mode 1 represents the larger part of the variability observed over South America in the GRACE 308 solutions. It is logically correlated to the largest number of in situ stations used in this study (9 309 among 18 or $50 \%$ with $|\mathrm{R}|>0.65$ for the regional solutions), and to in situ stations (Fig. 1) located 310 in a neighborhood of an extremum or a secondary extremum in the spatial component. 311 Correlations are generally higher for the regional solutions, than for the ICA and GRGS 312 solutions, even if the values are quite high for all type of solutions. High correlation $(>0.8)$ is 313 observed in Obidos located at $\sim 1500 \mathrm{~km}$ upstream to the mouth of the Amazon, for all type of 314 solutions with different time-delays between the GRACE solutions and the in situ measurements: $315-20 / 30 /-120$ days between regional/ICA/GRGS solutions and water levels in Obidos respectively 316 (Table 5). The zero time-lag corresponds to the region of maximum of signal located between 317 Jatuarana and Obidos (see Fig. 1), in the centre of the downstream Amazon along its mainstem. 318 The opposition of phase between the hydrological signals in the Orinoco and the Amazon basins 319 clearly appears in the time lags for Obidos and Ciudad Bolivar in the regional and ICA solutions. 320 A higher delay is observed upstream in the Madeira tributary at Fazenda Vista Alegre, a much 321 higher one in Manaus, due to the control of the Negro river flow by the Solimões or backwater 322 effect (Meade et al., 1991). On the contrary, negative time-lag is found for the Xingu river, in the 323 regional, and mostly, in the ICA solutions (except for Itaituba and Manaus).

324 This confirms that the Regional solutions are more accurate as they are both spatially and 325 temporally better localized than the global solutions. A large decrease of mass can be identified 326 in the Patagonian Icefield between 2003 and 2009, as a positive trend in the temporal component 
327 is multiplied by negative values in the spatial component. This confirms what was already 328 observed by Chen et al. (2007) using GRACE data.

330 The spatial components of the second mode of PCA are presented in Fig. 4a-c for Regional $331\left(\sigma^{2}=0.2\right)$, ICA $\left(\sigma^{2}=0.15\right)$, and GRGS $\left(\sigma^{2}=0.14\right)$ land water solutions, respectively. The extrema 332 present in the Regional (Fig. 4a) and ICA (Fig. 4b) are centred on the Orinoco and the Negro 333 basins (i.e., negative patterns in the northern part of South America), the southern bank of the 334 Solimões, the region covered with both Pindare and Parnacaiba basins, and the downstream part 335 and the delta of La Plata basin (positive patterns in the western, eastern, and south eastern parts of 336 the continent respectively). These structures are in good agreement with the distribution of 337 surface water from GLWD (Fig. 4d). The spatial patterns of the $2^{\text {nd }}$ mode of PCA for the GRGS 338 is quite different, as a large negative pattern appears on the central corridor of the Amazon, at the 339 junction between the Solimões, Negro and Madeira rivers, and no positive pattern over the 340 southern bank of the Solimões, and neither in the region covered with Pindare and Parnacaiba 341 basins.

342 Four in situ stations $(\sim 20 \%)$ were found to have high correlations with the $2^{\text {nd }}$ mode temporal 343 mode of the PCA of the GRACE-derived TWS (Table 5). Three of them are located in the 344 Amazon basin: one in the Branco basin, sub-basin of the Negro basin, northern Amazon where 345 high correlations are obtained $(|\mathrm{R}|>0.8)$, especially for the regional and the ICA solutions, and 346 two in the Solimões basin, at its entrance (Tabatinga) and its mouth (Manacapuru). For these two 347 latter stations, high correlations are found between in situ water levels and GRACE-based TWS 348 from regional and ICA solutions, but not from GRGS $(\mathrm{R}<0.5)$ (Table 5). The last one is located 349 in La Plata basin and better agreement is found between these water level records and GRGS- 
derived solutions than regional-derived and ICA-derived solutions. This appears clearly on Fig. 5

351 presenting the temporal component of the $2^{\text {nd }}$ PCA mode for each set of GRACE solutions (Fig.

352 5a) and the time-series of in situ water levels for these 4 four stations (Fig. 5b). A time lag of nine 353 months clearly separate the maxima of regional and ICA solutions (i.e., northern hemisphere 354 summer 2009) to the maximum of GRGS solutions (i.e., northern hemisphere winter 2010). They 355 respectively correspond to the extreme flood that affected the Amazon basin in 2009 (Marengo et 356 al., 2011) and to a flooding event occurring in La Plata basin from December 2009 to April 2010 357 (Salvia et al., 2011).

3.2.3 Third mode of variability

359 The spatial component of the third PCA mode is presented in Fig. 6a-c for regional $\left(\sigma^{2}=0.13\right)$, 360 ICA $\left(\sigma^{2}=0.14\right)$, and GRGS $\left(\sigma^{2}=0.1\right)$ land water solutions respectively (Table 2$)$. As for mode 2 , a 361 better agreement is found between regional and ICA solutions than between regional and GRGS 362 solutions, with correlation coefficients equal to 0.69 and 0.46 respectively (Table 3 ). The maxima 363 in the regional (Fig. 6a) and ICA (Fig. 6b) are located in the southern bank of the Solimões and 364 the central corridor of the Amazon river up to its junction with the Tapajos river, and the 365 upstream part of the Tocantins basin. Once again, this structure is in good agreement with the 366 distribution of surface water from GLWD (Fig. 6d). Some secondary extrema can also be 367 observed in the Negro basin in Argentina, over the Patagonia Icefield and Deseado basin in 368 Patagonia in the south. In the north, extrema are centred over the Essequibo (Guyana), Suriname 369 (Suriname), Oyapok and Maroni (French Guiana) basins (negative). GRGS solutions show that 370 the extrema are located around the central corridor of the Amazon river: negative in the north 371 (northern tributaries and Orinoco). Positive extrema appear in the south and over the Tocantins, 372 Pindare, and Parnacaiba basins for the GRGS solutions. 
373 Its temporal component was found to be correlated ( $|R|>0.7)$ to the time-variations of three in 374 situ stations ( 15\%) located in the Tocantins (Tucurui) and the eastern and southern parts of La 375 Plata (Chapeton and Pepiri Mini), for the regional and ICA solutions. However, the temporal 376 mode for the GRGS solutions is not correlated to in situ records (Table 5).

378 The spatial component of the fourth PCA mode is presented in Fig. 8a-c for regional $\left(\sigma^{2}=0.11\right)$, 379 ICA $\left(\sigma^{2}=0.1\right)$, and GRGS $\left(\sigma^{2}=0.08\right)$ land water solutions respectively (Table 2). Correlation is 380 much higher between regional and GRGS solutions $(\mathrm{R}=0.86)$ than between regional and ICA 381 solutions $(\mathrm{R}=0.46)$ (Table 3$)$. North-south stripes clearly appear for the ICA solutions (Fig. 8b). 382 Patterns of TWS seem to be related to the spatial distribution of groundwater recharge from 383 WHYMAP (Fig. 8d). Positive and negative extrema of TWS are located over regions where 384 recharge is maximum: the central corridor of the Amazon river, the downstream part of the Tocantins, the Pindare and the Parnacaiba, and the eastern part of La Plata basin (Fig. 8d). They 386 correspond to the locations of the largest aquifers of South America: Amazonas and Maranhão basins, Guarani Aquifer System respectively (Margat, 2007), and to a region of high to very high recharge according to WHYMAP, located between the two latter basins, which makes part of the groundwater footprint (i.e., the area required to sustain groundwater use and groundwaterdependent ecosystem services of a region of interest, such as an aquifer, watershed or community) of the Maranhão according to Gleeson et al. (2012) (see Fig. 1 of this paper). The temporal component of the fourth mode is highly correlated to the time-series of water levels of two in situ stations ( 10\%) located in the São Francisco and the Negro (in Argentina) basins. 
398 By dividing the water volume variations by the total ocean surface $\left(\sim 360\right.$ millions of $\left.\mathrm{km}^{2}\right)$, the 399 Equivalent Sea Level (ESL) time series are simply obtained (Fig. 10). They correspond to the 400 water mass contributions of these drainage basins to the actual measured sea level. The ESL time 401 series of regional, GRGS and ICA-400 km solutions remain very close to each other. However, 402 GRGS-based solutions present slightly greater amplitudes when they are averaged over the South 403 American basins. In general, the ESL time series are dominated by a strong seasonal cycle, as 404 previous shown by Ramillien et al. (2008b) while using 3-year GRACE data, that reaches +/-2 $405 \mathrm{~mm}$ for the Amazon river basin. This latter river basin appears as the largest contributor of water mass to the oceans at annual time scale, while the three others have amplitudes of $+/-0.5 \mathrm{~mm}$ 407 ESL. Besides, these series exhibit clear multi-year variations and modulations of the dominant 408 seasonal cycle: in the case of the Amazon, the maxima are important (up to $4 \mathrm{~mm}$ ESL) in 2006, 2008 and 2009 only, whereas the curve for La Plata basin contains short wavelengths with 410 maxima of seasonal cycle in 2003, 2007 and 2010. As both time-series of 10-day solutions (i.e., 411 regional and GRGS) exhibit important "high-frequency" variations, their origin seems to be 412 related to sub-monthly hydrological events. Analysis of daily water levels over 37 years (1961 413 1997) at Corrientes, the closest station to the mouth of La Plata basin, shows larger standard 414 deviations for a lower annual cycle than a similar analysis performed in Obidos (over 27 years), 415 the closest station to the mouth of La Plata basin (Clarke et al., 2000). This suggests important 416 short-term hydrological variations in the surface reservoir that can account for the rapid 417 variations observed in Fig. 10d. 
420 The contribution to sea level variations at interannual time-scale of the largest drainage basins of

421 South America (i.e., Amazon, Orinoco, and Tocantins) is presented on Fig. 11. If the 12-month

422 cycle is removed by applying a 13-month average sliding window on each ESL time-series, it is

423 clear the inter-annual residuals will not be explained by a simple linear trend for the considered

424 2003-2010 period (Fig. 11). The signatures of the extreme and sudden climatic events that

425 recently affected the Amazon basin as the droughts of 2005 and 2010 and the flood of 2009 (Fig.

426 11a), and La Plata such as the drought of 2009 and the flood of 2010 (Fig. 11d) can be clearly

427 identified. This is in contradiction with the self-made idea that continents would provide (or

428 retain) water mass to the oceans continuously, by suggesting multi-year variations do not permit

429 to establish a definitive water mass balance. Moreover, errors in the determination of the long-

430 term mass balance remain comparable to the fitted linear trend values themselves $(\sim 0.03 \mathrm{~mm} / \mathrm{yr})$,

431 according to Ramillien et al. (2008b). In the case of spherical harmonics representation (i.e.,

432 GRGS and ICA solutions), most of uncertainty (up to $0.05 \mathrm{~mm}$ ESL) is due to spectral leakage

433 (i.e., pollution of signals from other parts of the globe) because of truncation at degree 50-60

434 (Frappart et al., 2011b). This motivates us to compare the inter-annual variations to independent

435 datasets such as discharge change measurements versus time, to confirm the quality of our water

436 mass estimates computed from the different GRACE datasets. The interannual variations of TWS

437 are compared to the interannual variations of river discharges for these large drainage basins of

438 South America. They exhibit similar patterns as already observed in the Amazon basin and its

439 sub-basins using the ICA solutions (Frappart et al., 2012; in press). High correlations (R $\geq 0.9$ )

440 were found in the Amazon basin with one month of delay between TWS and discharge (Table 6).

441 This delay can be accounted for the presence of extensive floodplains along the central corridor

442 of the Amazon-Solimões, and over Negro (northern tributary of the Amazon) and Mamoré

443 basins, that cover more than $300,000 \mathrm{~km}^{2}$ of the surface of the basin (Diegues, 1994; Junk, 1997). 
444 The presence of floodplains delays the transit of surface water. As a consequence, TWS is 445 dominated by surface water causing a time-shift between TWS and discharge. On the contrary, 446 for basins less densely covered with floodplains as the Orinoco and La Plata, correlation in time 447 between TWS and discharge remains high (R 0.7 except for the ICA solutions with R 0.6 and $448 \mathrm{R}>0.75$ except for the ICA solutions with $\mathrm{R} \sim 0.6$ respectively), however the time shift is negative: 449 maximum of discharge occurs one or two months before the maximum of TWS (Table 6). In the

450 Tocantins basin, correlation between TWS and discharge is much lower $(\mathrm{R}<0.6)$ most likely 451 because the interannual variations of TWS are more influenced by the groundwater storage, as 452 the region is characterized by the presence of a large aquifer system (Maranhão basin).

\section{Conclusion}

2-by-2 degree regional water mass solutions over South America were compared to GRACE456 based global products (GRGS and ICA-400) for the period 2003-2010, and it is shown that they 457 offer a better geographical location of hydrological structures by construction than global 458 solutions. As a consequence, the higher power spectral density present in the regional solution at 459 at smaller spatial scales can be attributed to a better determination of these wavelengths in the 460 regional solutions. Besides, the global GRGS solutions suffer from the presence of residuals 461 North-South striping from aliasing, this effect masks the hydrological structures, and 462 consequently degrades the water mass balance estimates. Principal Component Decomposition of 463 all the GRACE datasets permitted us to unravel modes of variability from observed signals 464 observed by GRACE, and then identify geographical locations of inter-annual water mass 465 variations of individual groundwater unit over the continent, and correlate them to climatology. 466 Robust validation of these GRACE datasets consists of comparing them to time variations of in 467 situ water level and discharge measurements. Correlations between GRACE solutions and river 
level records are significant for the four first PCA modes suggesting these modes represent water mass changes at the surface of the Earth. In particular, signature of the melt of the Patagonian IceField in the gravity field is found in temporal modes 1 and 3 while its location is well

471 identified in the corresponding spatial modes. Temporal mode number 4 seems to be mostly 472 related to slower groundwater variations, as the corresponding spatial mode clearly coincides 473 with the geographical limits of groundwater unit. High correlations are also found between TWS and river discharges at interannual time-scale in the Amazon and Orinoco basins where TWS is 475 dominated by the surface reservoir due to the presence of extensive floodplains, whereas low 476 correlation is found for the Tocantins, likely because the measured gravity signal is dominated by 477 groundwater changes in this basin. Our study, based on the use of PCA, demonstrated the ability 478 of GRACE satellite gravimetry to distinguish efficiently real hydrological signals in different reservoirs (surface waters, groundwater, glaciers) especially through such a regional approach.

\section{Acknowledgements}

The authors would like to thank Dr. Wilhelm Struckmeier and Dipl.-Geogr. Andrea Richts from BGR for letting us use the WHYMAP map of groundwater resources in their paper.

\section{References}

Alsdorf, D. E., \& Lettenmaier, D.P. (2003). Tracking fresh water from space. Science, 301, 14921494.

Andersen, O. B., Seneviratne, S.I., Hinderer, J. \& Viterbo, P. (2005). GRACE-derived terrestrial water storage depletion associated with the 2003 European heat wave. Geophysical Research Letters, 32(18), L18405.

Awange, J.L., Fleming, K.M., Kuhn, M., Featherstone, W.E., Heck, B., \& Anjasmara, I. (2011). On the suitability of the $4^{\circ} \times 4^{\circ}$ GRACE mascon solutions for remote sensing Australian hydrology. Remote Sensing of Environment, 115(3), 864-875. 
Bergmann, I., Ramillien, G., \& Frappart, F. (2012). Climate-driven interannual variations of the mass balance of Greenland. Global and Planetary Change, 82-83, 1-11, doi: 10.1016/j.gloplacha.2011.

Bruinsma, S., Lemoine, J-M., Biancale, R., \& Valès, N. (2010). CNES/GRGS 10-day gravity models (release 2) and their evaluation. Advances in Space Research, 45(4), 587-601, doi:10.1016/j.asr.2009.10.012.

Chen, J.L., Wilson, C.R., Tapley, B.D., Blankenship, D.D., \& Ivins, E.R. (2007). Patagonia Icefield melting observed by Gravity Recovery and Climate Experiment (GRACE). Geophysical Research Letters, 34(22), L22501.

Chen, J.L., Wilson, C.R., Tapley, B.D., Yang, Z.L. \& Niu G.Y. (2009). 2005 drought event in the Amazon River basin as measured by GRACE and estimated by climate models, Journal of Geophysical Research, 114, B05404, doi:10.1029/2008JB006056.

Chen, J.L., Wilson, C.R., \& Tapley, B.D. (2010a). The 2009 exceptional Amazon flood and interannual terrestrial water storage change observed by GRACE. Water Resources Research, 46(12), W12526. doi: 10.1029/2010WR009383.

Chen, J.L., Wilson, C.R., Tapley, B.D., Longuevergne, L., Yang, Z.L., \& Scanlon, B.R. (2010b). Recent La Plata basin drought conditions observed by satellite gravimetry. Journal of Geophysical Research, 115, D22108, doi: 10.1029/2010JD014689.

Clarke, R.T., Mendiondo, E.M., \& Brusa L.C. (2000). Uncertainties in mean discharges from two large South American rivers due to rating curve variability. Hydrological Sciences JournalJournal Des Sciences Hydrologiques, 45(2), 221-236.

Diegues A.C.S. (ed.) (1994). An Inventory of Brazilian Wetlands, International Union for Conservation of Nature, Gland, Switzerland, 224 pp.

Döll, P., \& Fiedler, K. (2008). Global-scale modeling of groundwater recharge. Hydrology and Earth System Sciences, 12, 863-885, doi:10.5194/hess-12-863-2008.

Eicker, A. (2008). Gravity Field Refinement by Radial Basis Functions from In-situ Satellite Data. Dissertation Univ. Bonn D 98, pp. 137, Univ. Bonn, Bonn, Germany.

Frappart, F., Papa, F., Famiglietti, J.S., Prigent, C., Rossow, W.B., \& Seyler, F. (2008). Interannual variations of river water storage from a multiple satellite approach: a case study for the Rio Negro River basin. Journal of Geophysical Research, 113(D21), D21104, doi: 10.1029/2007JD009438.

Frappart, F., Ramillien, G., Maisongrande, P., \& Bonnet, M-P. (2010). Denoising satellite gravity signals by independent component analysis. IEEE Geoscience and Remote Sensing Letters, 7(3), 421-425, doi:10.1109/LGRS.2009.2037837. 
Frappart, F., Ramillien, G., \& Famiglietti, J.S. (2011a). Water balance of the Arctic drainage system using GRACE gravimetry products. International Journal of Remote Sensing, 32(2), 431453, doi: 10.1080/01431160903474954.

Frappart, F., Ramillien, G., Leblanc, M., Tweed, S.O., Bonnet, M-P., \& Maisongrande, P. (2011b). An independent component analysis approach for filtering continental hydrology in the GRACE gravity data. Remote Sensing of Environment, 115(1), 187-204, doi:10.1016/j.rse.2010.08.017.

Frappart, F., Papa, F., Güntner, A., Werth, S., Santos da Silva, J., Seyler, F., Prigent, C., Rossow, W.B., Calmant, S., \& Bonnet, M-P. (2011c). Satellite-based estimates of groundwater storage variations in large drainage basins with extensive floodplains. Remote Sensing of Environment, 115(6), 1588-1594, doi: 10.1016/j.rse.2011.02.003.

Frappart, F., Papa, F., Santos da Silva, J., Ramillien, G., Prigent, C., Seyler, F., \& Calmant, S. (2012). Surface freshwater storage in the Amazon basin during the 2005 exceptional drought. Environmental Research Letters, 7(4), 044010, doi:10.1088/1748-9326/7/044010.

Frappart, F., Ramillien, G., \& Ronchail, J., (in press). Changes in terrestrial water storage vs. rainfall and discharges in the Amazon basin. International Journal of Climatology, in press.

Freeden, W., \& Schreiner, M. (2008). Spherical Functions of Mathematical Geosciences: A Scalar, Vectorial, and Tensorial Setup, Springer, Heidelberg, 602 pp.

Gleeson, T., Wada, Y., Bierkens, M.F.P., \& van Beek, L.P.H. (2012). Water balance of global aquifers revealed by groundwater footprint. Nature, 488, 197-200, doi: 10.1038/nature11295.

Han, S-C., Kim, H., Yeo, I.Y., Yeh, P., Oki, T., Seo, K.W., Alsdorf, D., \& Luthcke, S.B. (2009). Dynamics of surface water storage in the Amazon inferred from measurements of inter-satellite distance change. Geophysical Research Letters, 36, L09403, doi: 10.1029/2009GL037910.

Junk, W.J. (1997). General aspects of floodplain ecology with special reference to Amazonian floodplains, in The central Amazon floodplain: Ecology of a pulsing system (Junk, W.J., Piedade, M.T.F., Wittmann, F., Schöngart, J., \& Parolin, P., eds), 3-20, Springer-Verlag, Berin \& Heidelberg, Germany.

Kim, H., Yeh, P.J.F., Oki, T., \& Kanae, S. (2009). Role of rivers in the seasonal variations of terrestrial water storage over global basins. Geophysycal Research Letters, 36, L17402, doi: 10.1029/2009GL039006.

Klees, R., Liu, X., Wittwer, T., Gunter, B.C., Revtova, E.A., Tenzer, R., Ditmar, P., Winsemius, H.C., \& Savenije, H.H.G. (2008). A comparison of global and regional GRACE models for land hydrology. Surveys in Geophysics, 29(4-5), 335-359.

Lehner, B., \& Döll, P. (2004). Development and validation of a global database of lakes, reservoirs and wetlands. Journal of Hydrology, 296(1-4), 1-22. 
Leblanc, M. J., Tregoning, P., Ramillien, G., Tweed, S.O., \& Fakes, A. (2009). Basin - scale, integrated observations of the early 21st century multiyear drought in southeast Australia. Water Resources Research, 45, W04408, doi:10.1029/2008WR007333. (2007). Temporal gravity field models inferred from GRACE data. Advances in Space Research, 39(10), 1620-1629.

593

Marengo, J.A., Tomasella, J., Soares, W., Alves, L.M., \& Nobre, C. (2011). Extreme climatic events in the Amazon basin: climatological and hydrological context of recent floods. Theoretical and Applied Climatology, 107(1-2), 73-85, doi: 10.1007/s00704-011-0465-1.

Margat, J. (2007). Great aquifer systems of the world. In Aquifer Systems Management: Darcy's Legacy in a World of Impending Water. Chery L. and de Marsily G. (Eds.), 105-116, Taylor and Francis, Oxford, England.

Meade, R.H., Rayol, J.M., Conceição, S.C., \& Navidade, J. R.G. (1991). Backwater effects in the Amazon basin of Brazil. Environmental Geology and Water Science, 18, 105-14.

Pereira, A., Pacino, M.C. (2012). Annual and seasonal water storage changes detected from GRACE data in the La Plata Basin. Physics of the Earth and Planetary Interiors, 212-213, 8899, doi: 10.1016/j.pepi.2012.09.005.

Ramillien, G., Frappart, F., Cazenave, A., \& Güntner, A. (2005). Time variations of land water storage from the inversion of 2-years of GRACE geoids. Earth and Planetary Science Letters, 235(1-2), 283-301, doi:10.1016/j.eps1.2005.04.005.

Ramillien, G., Frappart, F., Güntner, A., Ngo-Duc, T., Cazenave, A. \& Laval, K. (2006). Time variations of the regional evapotranspiration rate from Gravimetry Recovery And Climate Experiment (GRACE) satellite gravimetry. Water Resources Research, 42, W10403, doi:10.1029/2005WR004331.

Ramillien, G., Famiglietti, J.S., \& Wahr, J. (2008a). Detection of continental hydrology and glaciology signals from GRACE: a review. Surveys in Geophysics, 29, 361-374, doi: 10.1007/s10712-008-9048-9.

Ramillien, G., Bouhours, S., Lombard, A., Cazenave, A., Flechtner, F., \& Schmidt, R. (2008b). Land water storage contribution to sea level from GRACE geoid data over 2003-2006. Global and Planetary Change, 60(3-4), 381-392, doi:10.1016/j.gloplacha.2007.04.002.

Ramillien, G., Biancale, R., Gratton, S., Vasseur, X., \& Bourgogne, S. (2011). GRACE-derived surface mass anomalies by energy integral approach. Application to continental hydrology. Journal of Geodesy, 85(6), 313-328, doi:10.1007/s00190-010-0438-7.

629 
630

631

632

633

634

635

636

637

638

639

640

641

642

643

644

645

646

647

648

649

650
Ramillien, G., Seoane, L., Frappart, F., Biancale, R., Gratton, S., Vasseur, X., \& Bourgogne, S. (2012). Constrained regional recovery of continental water mass time-variations from GRACEbased geopotential anomalies over South America. Surveys in Geophysics, 33, 887-905, doi: 10.1007/s10712-012-9177-z.

Richts, A., Struckmeier, W.F., \& Zaepke, M. (2011). WHYMAP and the groundwater resources map of the world 1:25,000,000, In Sustaining Groundwater Resources: A Critical Element in the Global Water Crisis, Jones J.A.A. (Ed.), 159-173, Springer, Netherlands, doi: 10.1007/978-903426-7_10.

Rodell, M., Famiglietti, J.S., Chen, J., Seneviratne, S.I., Viterbo, P., Holl S. \& Wilson C.R. (2004). Basin scale estimates of evapotranspiration using GRACE and other observations. Geophysycal Research Letters, 31(20), L20504.

Rodell, M., Chen, J., Kato, H., Famiglietti, J.S., Nigro, J. \& Wilson, C. (2007). Estimating groundwater storage changes in the Mississippi River basin (USA) using GRACE. Hydrogeology Journal, 15(1), 159-166.

Rowlands D.D., Luthcke, S.B., Klosko, S.M., Lemoine, F.G.R., Chinn, D.S., McCarthy, J.J., Cox, C.M., \& Anderson, O.B. (2005). Resolving mass flux at high spatial and temporal resolution using GRACE intersatellite measurements. Geophysical Research Letters, 32, L04310, doi:10.1029/2004GL021908.

Rowlands, D.D., Luthcke, S.B., McCarthy, J.J., Klosko, S.M., Chinn, D.S., Lemoine, F.G., Boy, J-P., \& Sabaka, T.J. (2010). Global mass flux solutions from GRACE: A comparison of parameter estimation strategies - Mass concentrations versus Stokes coefficients. Journal of Geophysical Research, 115, B01403, doi:10.1029/2009JB006546.

Salvia, M., Grings, F., Ferrazzoli, P., Barraza, V., Douna, V., Perna, P., Bruscantini, C. \& Karszenbaum, H. (2011). Estimating flooded area and mean water level using active and passive microwaves: the example of Parana River Delta floodplain. Hydrology and Earth System Sciences, 15, 2679-2692, doi: 10.5194/hess-15-2679-2011.

Schmidt, R., Flechtner, F., Meyer, U., Neumayer, K.-H., Dahle, Ch., Koenig, R., \& Kusche, J. (2008). Hydrological Signals Observed by the GRACE Satellites. Surveys in Geophysics, 29, 319-334, doi: 10.1007/s10712-008-9033-3.

Seitz, F., Schmidt, M. \& Shum, C.K. (2008). Signals of extreme weather conditions in Central Europe in GRACE 4-D hydrological mass variations, Earth and Planetary Science Letters, 268(1-2), 165-170.

Strassberg, G., Scanlon, B. R., \& Rodell, M. (2007). Comparison of seasonal terrestrial water storage variations from GRACE with groundwater-level measurements from the High Plains Aquifer (USA). Geophysical Research Letters, 34, L14402, doi:10.1029/2007GL030139. 
667 Syed, T.H., Famiglietti, J.S., \& Chambers, D. (2009). GRACE-based estimates of terrestrial 668 freshwater discharge from basin to continental scales. Journal of Hydrometeorology, 10(1), doi: 669 10.1175/2008JHM993.1.

670 Tapley, B.D., Bettadpur, S., Ries, J.C., Thompson, P.F., \& Watkins M. (2004). GRACE 671 measurements of mass variability in the Earth system. Science, 305, 503-505.

672 Tomasella, J., Borma, L.S., Marengo, J.A., Rodriguez, D.A., Cuartas, L.A., Nobre, C.A., Prado, 673 M.C.R. (2011). The droughts of 1996-1997 and 2004-2005 in Amazonia: hydrological response 674 in the river main-stem. Hydrological Processes, 25, 1228-1242, doi: 10.1002/hyp.7889.

675 


\section{List of Tables}

678 Table 1 : List of the in situ stations used for comparisons with GRACE-derived TWS over the 679 largest river basins South America (Amazon, La Plata, Orinoco, Tocantins, São Francisco, 680 Negro) and their tributaries.

681

682 Table 2 : Explained variances for the four first modes of the Principal Components Analysis 683 (PCA) of centred and deseasonalized TWS from GRACE for the regional solutions, the ICA684 filtered solutions from CSR, GFZ, and JPL, and the GRGS solutions over the 2003-2010 time685 period.

686 Table 3 : Correlation between the spatial component of the different GRACE solutions (regional, 687 ICA-CSR-400km, and GRGS) for each PCA mode.

688 Table 4: Correlation between the temporal component of the different GRACE solutions 689 (regional, ICA-CSR-400km, and GRGS), and maximum correlation and associated time-lag for 690 each PCA mode.

691 Table 5 : Correlation value corresponding to maximum of module of correlation and associated 692 time-lag (days) between interannual variations of in situ water levels and GRACE-based TWS for 693 regional, ICA (CSR), and GRGS solutions.

694 Table 6 : Maximum correlation and associated time-lag (months) between interannual variations 695 of GRACE-based TWS (expressed in ESL) for regional, ICA (CSR), and GRGS solutions of in 696 situ river discharge in Obidos - Amazon, Ciudad Bolivar - Orinoco, Tucurui - Tocantins, and 697 Chapeton - La Plata. 


\section{List of Figures}

701 Figure 1 : Major drainage basins of South America: Orinoco (light green), Amazon (dark blue), stations are represented with red circles (HYBAM), black squares (ANA), and green triangles (INA).

Figure 2 : Spatial component of the $1^{\text {st }}$ PCA mode of TWS for a) Regional $\left(\sigma^{2}=0.43\right)$, b) ICACSR $\left(\sigma^{2}=0.44\right)$, and c) GRGS $\left(\sigma^{2}=0.6\right)$ solutions over 2003-2010. d) GLWD map of surface water over South America. In the dashed blue rectangles, regions of maximum or minimum of TWS signal: 1 - Altiplano, 2 - Solimões-Amazon corridor (including the south of the Amazonian Negro basin) + mouth of the Tocantins, 3 - Pindare and Parnacaiba, 4 - La Plata delta. In the dashed green rectangles, secondary extrema of TWS: 1 - Mouth of the Orinoco, 2 - Sources of Parana (La Plata) and São Francisco rivers, 3 - Patagonia Icefield and Deseado basin.

Figure 3 : a) Temporal component of the $1^{\text {st }}$ PCA mode of TWS for Regional (black), ICA-CSR (red), and GRGS (blue) solutions over 2003-2010. b) Time variations of normalized water levels correlated with the $1^{\text {st }}$ PCA mode: Ciudad Bolivar (black), Serrinha (red), Manaus (blue), Fazenda Vista Alegre (light green), Jatuarana (grey), Obidos (orange), Itaituba (yellow), Porto de Moz (dark green), Batallon 601 (light blue).

717 Figure 4 : Spatial component of the $2^{\text {nd }}$ PCA mode of TWS for a) Regional $\left(\sigma^{2}=0.2\right)$, b) ICA$\operatorname{CSR}\left(\sigma^{2}=0.15\right)$, and c) GRGS $\left(\sigma^{2}=0.14\right)$ solutions over 2003-2010. d) GLWD map of surface water over South America. In the dashed blue rectangles, regions of maximum or minimum of TWS signal: 1 - Orinoco and the Negro basins, 2 - the southern bank of the Solimões, 3 - the region covered with Pindare and Parnacaiba basins, 4 - the downstream part and the delta of La Plata basin.

723 Figure 5 : a) Temporal component of the $2^{\text {nd }}$ PCA mode of TWS for Regional (black), ICA-CSR (red), and GRGS (blue) solutions over 2003-2010. b) Time variations of normalized water levels correlated with the $2^{\text {nd }}$ PCA mode: Caracarai (black), Tabatinga (red), Manacapuru (blue), Corrientes (green).

Figure 6 : Spatial component of the $3^{\text {rd }}$ PCA mode of TWS for a) Regional $\left(\sigma^{2}=0.13\right)$, b) ICA$\operatorname{CSR}\left(\sigma^{2}=0.14\right)$, and c) GRGS $\left(\sigma^{2}=0.1\right)$ solutions over 2003-2010. d) GLWD map of surface water over South America. In the dashed blue rectangles, regions of maximum or minimum of TWS signal: 1 - southern bank of the Solimões and the central corridor of the Amazon until the junction with the Tapajos river 2 - upstream part of the Tocantins. In the dashed green rectangles,

732 secondary extrema of TWS: 1 - Negro basin, 2 - Patagonia Icefield and Deseado basin, 3 733 Essequibo (Guyana), Suriname (Suriname), Oyapok and Maroni (French Guiana) basins. 
734 Figure 7 : a) Temporal component of the $3^{\text {rd }}$ PCA mode of TWS for Regional (black), ICA-CSR 735 (red), and GRGS (blue) solutions over 2003-2010. b) Time variations of normalized water levels 736 correlated with the $3^{\text {rd }}$ PCA mode: Tucurui (black), Pepiri Mini (red), Chapeton (blue).

737 Figure 8 : Spatial component of the $4^{\text {th }}$ PCA mode of TWS for a) Regional $\left(\sigma^{2}=0.11\right)$, b) ICA$738 \operatorname{CSR}\left(\sigma^{2}=0.1\right)$, and c) GRGS $\left(\sigma^{2}=0.08\right)$ solutions over 2003-2010. d) WHYMAP map of 739 groundwater recharge over South America. In the dashed black rectangles, regions of maximum 740 or minimum of TWS signal: 1 - Amazonas, 2 - Maranhão, 3 - Guarani aquifer systems (adapted 741 from Margat (2007)).

742 Figure 9 : a) Temporal component of the $4^{\text {th }}$ PCA mode of TWS for Regional (black), ICA-CSR 743 (red), and GRGS (blue) solutions over 2003-2010. b) Time variations of normalized water levels 744 correlated with the $4^{\text {th }}$ PCA mode: Piranhas (black), Primera Angostura (red).

745 Figure 10 : Time-series of GRACE-based TWS over 2003-2010 from Regional (black), ICA 746 CSR $400 \mathrm{~km}$ (red), GRGS (blue) expressed in mm of ESL for the a) Amazon, b) Orinoco, c) 747 Tocantins, and d) La Plata basins.

748 Figure 11 : Time-series of GRACE-based interannual TWS over 2003-2010 from Regional 749 (black), ICA CSR $400 \mathrm{~km}$ (red), GRGS (blue) expressed in mm of ESL and of interannual 750 discharge (grey) for the a) Amazon, b) Orinoco, c) Tocantins, and d) La Plata basins. 
Table 1 : List of the in situ stations used for comparisons with GRACE-derived TWS over the largest river basins South America (Amazon, La Plata, Orinoco, Tocantins, São Francisco, Negro) and their tributaries.

\begin{tabular}{lllll}
\multicolumn{1}{c}{ Station } & \multicolumn{1}{c}{ Basin } & Lon $\left(^{\circ}\right)$ & Lat $\left(^{\circ}\right)$ & Source \\
\hline Ciudad Bolivar & Orinoco & -63.608 & 8.439 & HYBAM \\
Caracarai & Branco (Amazon) & -61.124 & 1.814 & HYBAM \\
Serrinha & Negro (Amazon) & -64.289 & -0.485 & HYBAM \\
Manaus & Negro (Amazon) & -60.035 & -3.149 & ANA \\
Tabatinga & Solimões (Amazon) & -69.952 & -4.253 & HYBAM \\
Manacapuru & Solimões (Amazon) & -60.609 & -3.316 & HYBAM \\
Fazenda Vista Alegre & Madeira (Amazon) & -60.026 & -4.898 & HYBAM \\
Jatuarana & Amazon & -59.643 & -3.062 & ANA \\
Obidos & Amazon & -55.657 & -1.923 & HYBAM \\
Itaituba & Tapajos (Amazon) & -55.982 & -4.278 & HYBAM \\
Porto de Moz & Xingu (Amazon) & -52.240 & -1.753 & ANA \\
Tucurui & Tocantins & -49.683 & -3.783 & ANA \\
Piranhas & São Francisco & -37.756 & -9.626 & ANA \\
Corrientes & Parana (La Plata) & -58.833 & -27.475 & INA \\
Pepiri Mini & Uruguay (La Plata) & -53.933 & -27.154 & INA \\
Batallon 601 & Coronda (La Plata) & -60.746 & -31.694 & INA \\
Chapeton & Parana (La Plata) & -60.283 & -31.574 & INA \\
Primera Angostura & Negro & -63.790 & -40.456 & INA
\end{tabular}


Table 2 : Explained variances for the four first modes of the Principal Components Analysis (PCA) of centred and deseasonalized TWS from GRACE for the regional solutions, the ICAfiltered solutions from CSR, GFZ, and JPL, and the GRGS solutions over the 2003-2010 timeperiod.

\section{Explained}

variance $(\%)$

mode 1

mode 2

mode 3

mode 4

sum

$\begin{array}{lccccc}\text { regional } & 43 & 20 & 13 & 11 & 87 \\ \text { ICA CSR } & 44 & 15 & 14 & 10 & 83 \\ \text { ICA GFZ } & 42 & 17 & 13 & 10 & 82 \\ \text { ICA JPL } & 41 & 21 & 13 & 8 & 83 \\ \text { GRGS } & 60 & 14 & 10 & 8 & 92\end{array}$


Table 3 : Correlation between the spatial component of the different GRACE solutions (regional, ICA-CSR-400km, and GRGS) for each PCA mode.

R

PCA mode regional vs. ICA-CSR-400km

mode 1

mode 2

mode 3

mode 4

0.84

0.67

0.69

0.46
GRACE solutions

regional vs. GRGS ICA-CSR-400km vs. GRGS

$0.6 \quad 0.67$

0.43

$-0.04$

0.46

0.86
0.38

0.39 
Table 4: Correlation between the temporal component of the different GRACE solutions (regional, ICA-CSR-400km, and GRGS), and maximum correlation and associated time-lag for each PCA mode.

$\mathrm{R}$

PCA mode mode 1 $\mathrm{R}(\Delta \mathrm{t}=0)$ $R \max (\Delta \mathrm{t}$ in days) $\mathrm{R}(\Delta \mathrm{t}=0)$ mode 2 $R \max (\Delta \mathrm{t}$ in days $)$ $\mathrm{R}(\Delta \mathrm{t}=0)$

$R \max (\Delta \mathrm{t}$ in days $)$ $\mathrm{R}(\Delta \mathrm{t}=0)$

$\operatorname{Rmax}(\Delta \mathrm{t}$ in days)

GRACE solutions

regional vs. ICA-CSR-400km regional vs. GRGS ICA-CSR-400km vs. GRGS

0.95

$0.96(30)$

0.79

$0.91(-120)$

0.79

$0.79(0)$

0.62

$0.7(-120)$

0.82

0.84 (80)

0.52

$0.80(-160)$

0.56

$0.61(-60)$

0.96

$0.96(0)$

0.81

$0.86(180)$

0.08

$0.58(-180)$

0.17

$0.21(60)$

0.47

0.57 (180) 
Table 5 : Correlation value corresponding to maximum of module of correlation and associated time-lag (days) between interannual variations of in situ water levels and GRACE-based TWS for regional, ICA (CSR), and GRGS solutions.

\begin{tabular}{lccccccc} 
& \multicolumn{2}{c}{ regional } & \multicolumn{2}{c}{ ICA } & \multicolumn{2}{c}{ GRGS } \\
\multicolumn{1}{c}{ Station } & MCA & $\mathrm{R}$ & $\Delta \mathrm{t}$ & $\mathrm{R}$ & $\Delta \mathrm{t}$ & $\mathrm{R}$ & $\Delta \mathrm{t}$ \\
$\max (|\mathrm{R}|)$ & $(\mathrm{days})$ & $\max (|\mathrm{R}|)$ & $($ days $)$ & $\max (|\mathrm{R}|)$ & $($ days $)$ \\
\hline Ciudad Bolivar & 1 & -0.80 & 180 & -0.73 & 180 & -0.63 & 170 \\
Caracarai & 2 & -0.86 & -40 & -0.83 & 30 & -0.66 & -120 \\
Serrinha & 1 & 0.66 & -160 & 0.62 & -150 & 0.62 & -180 \\
Manaus & 1 & 0.65 & 120 & 0.65 & 60 & 0.50 & -180 \\
Tabatinga & 2 & 0.81 & -160 & 0.83 & -90 & 0.39 & -180 \\
Manacapuru & 2 & 0.91 & -180 & 0.83 & -90 & 0.47 & -180 \\
Fazenda Vista Alegre & 1 & 0.80 & 50 & 0.84 & 90 & 0.75 & -160 \\
Jatuarana & 1 & 0.70 & 30 & 0.70 & 60 & 0.58 & -180 \\
Obidos & 1 & 0.88 & -20 & 0.87 & 30 & 0.81 & -120 \\
Itaituba & 1 & 0.96 & 0 & 0.83 & -110 & 0.94 & 30 \\
Porto de Moz & 1 & 0.88 & -90 & 0.82 & 0 & 0.71 & -160 \\
Tucurui & 3 & 0.74 & -30 & 0.73 & 30 & 0.31 & -30 \\
Piranhas & 4 & 0.68 & -30 & 0.71 & -30 & 0.71 & -30 \\
Pepiri Mini & 3 & -0.70 & -150 & -0.80 & -120 & -0.16 & -180 \\
Corrientes & 2 & 0.71 & 70 & 0.52 & 60 & 0.90 & -100 \\
Batallón 601 & 1 & -0.67 & -110 & -0.62 & -90 & 0.25 & 180 \\
Chapeton & 3 & -0.77 & -160 & -0.72 & -150 & -0.39 & -180 \\
Primera Angostura & 4 & -0.70 & -150 & -0.52 & 180 & -0.77 & -150
\end{tabular}


Table 6 : Maximum correlation and associated time-lag (months) between interannual variations of GRACE-based TWS (expressed in ESL) for regional, ICA (CSR), and GRGS solutions of in situ river discharge in Obidos - Amazon, Ciudad Bolivar - Orinoco, Tucurui - Tocantins, and Chapeton - La Plata.

TWS regional TWS ICA TWS GRGS

\begin{tabular}{lrcrrrc} 
Discharge station & $\mathrm{Rmax}$ & $\Delta \mathrm{t}$ (months) & $\mathrm{Rmax}$ & $\Delta \mathrm{t}$ (months) & $\mathrm{Rmax}$ & $\Delta \mathrm{t}$ (months) \\
\hline Obidos (Amazon) & 0.9 & 1 & 0.93 & 1 & 0.92 & 1 \\
Ciudad Bolivar (Orinoco) & 0.69 & -1 & 0.58 & -1 & 0.69 & -2 \\
Tucurui (Tocantins) & 0.46 & 2 & 0.63 & 1 & 0.37 & 2 \\
Chapeton (La Plata) & 0.86 & -3 & 0.61 & -3 & 0.75 & -3
\end{tabular}




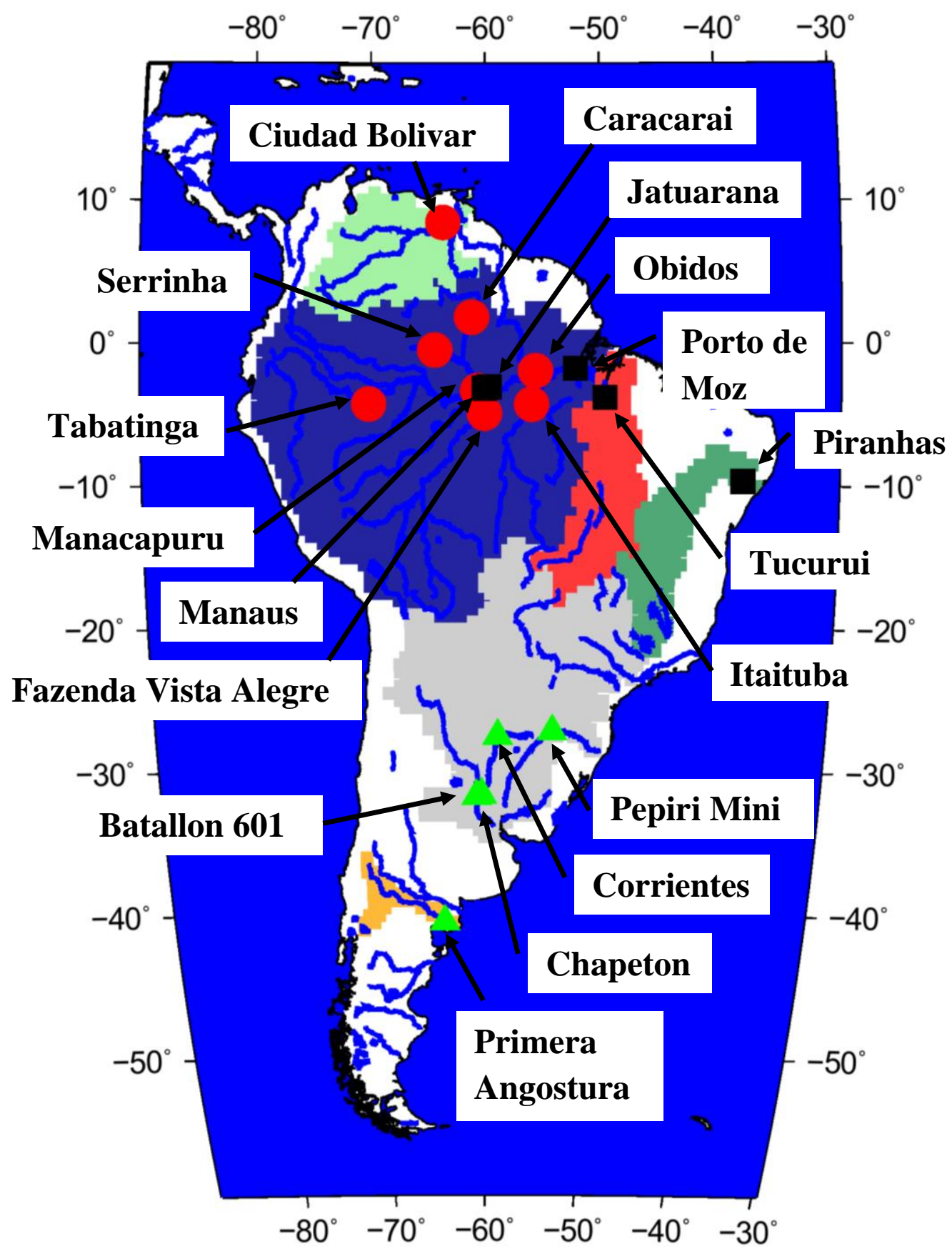

Figure 1 : Major drainage basins of South America: Orinoco (light green), Amazon (dark blue), Tocantins (red), São Francisco (dark green), La Plata (grey), Negro (orange). In situ gauge stations are represented with red circles (HYBAM), black squares (ANA), and green triangles (INA). 

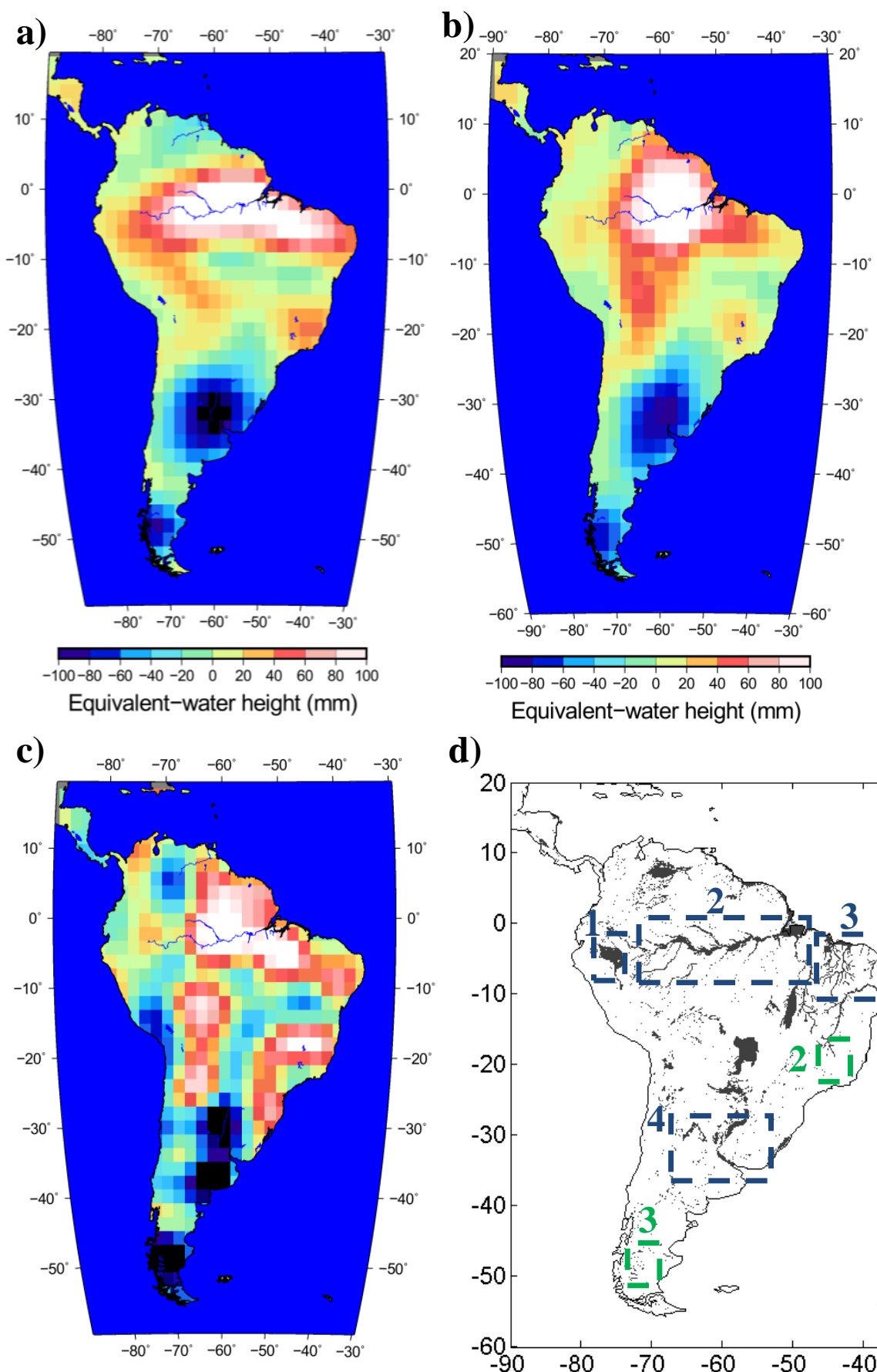

d)

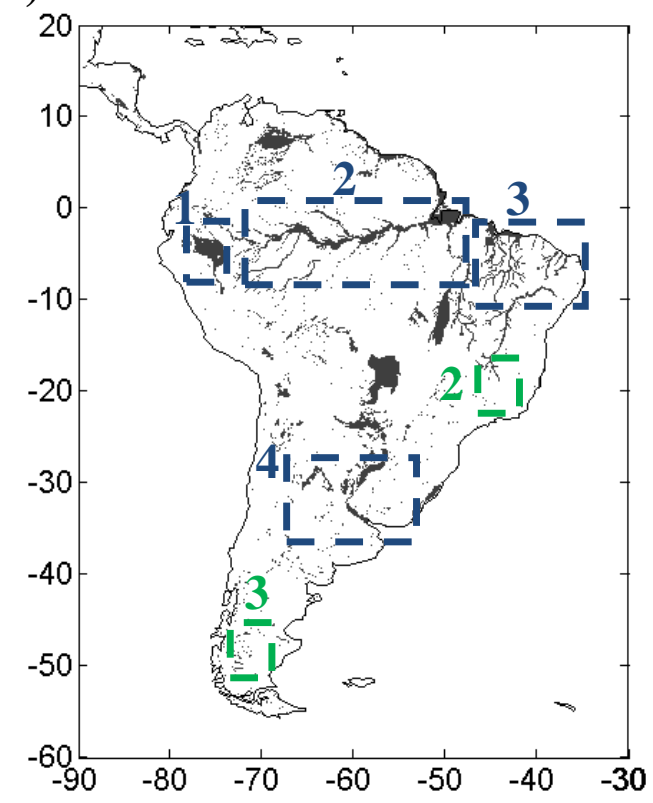

$-100-80-60-40-20 \quad 0 \quad 20 \quad 40 \quad 60 \quad 80100$

Equivalent-water height $(\mathrm{mm})$

Figure 2 : Spatial component of the $1^{\text {st }}$ PCA mode of TWS for a) Regional $\left(\sigma^{2}=0.43\right)$, b) ICA$\operatorname{CSR}\left(\sigma^{2}=0.44\right)$, and c) GRGS $\left(\sigma^{2}=0.6\right)$ solutions over 2003-2010. d) GLWD map of surface water over South America. In the dashed blue rectangles, regions of maximum or minimum of TWS signal: 1 - Altiplano, 2 - Solimões-Amazon corridor (including the south of the Amazonian Negro basin) + mouth of the Tocantins, 3 - Pindare and Parnacaiba, 4 - La Plata delta. In the dashed green rectangles, secondary extrema of TWS: 1 - Mouth of the Orinoco, 2 - Sources of Parana (La Plata) and São Francisco rivers, 3 - Patagonia Icefield and Deseado basin. 
a)

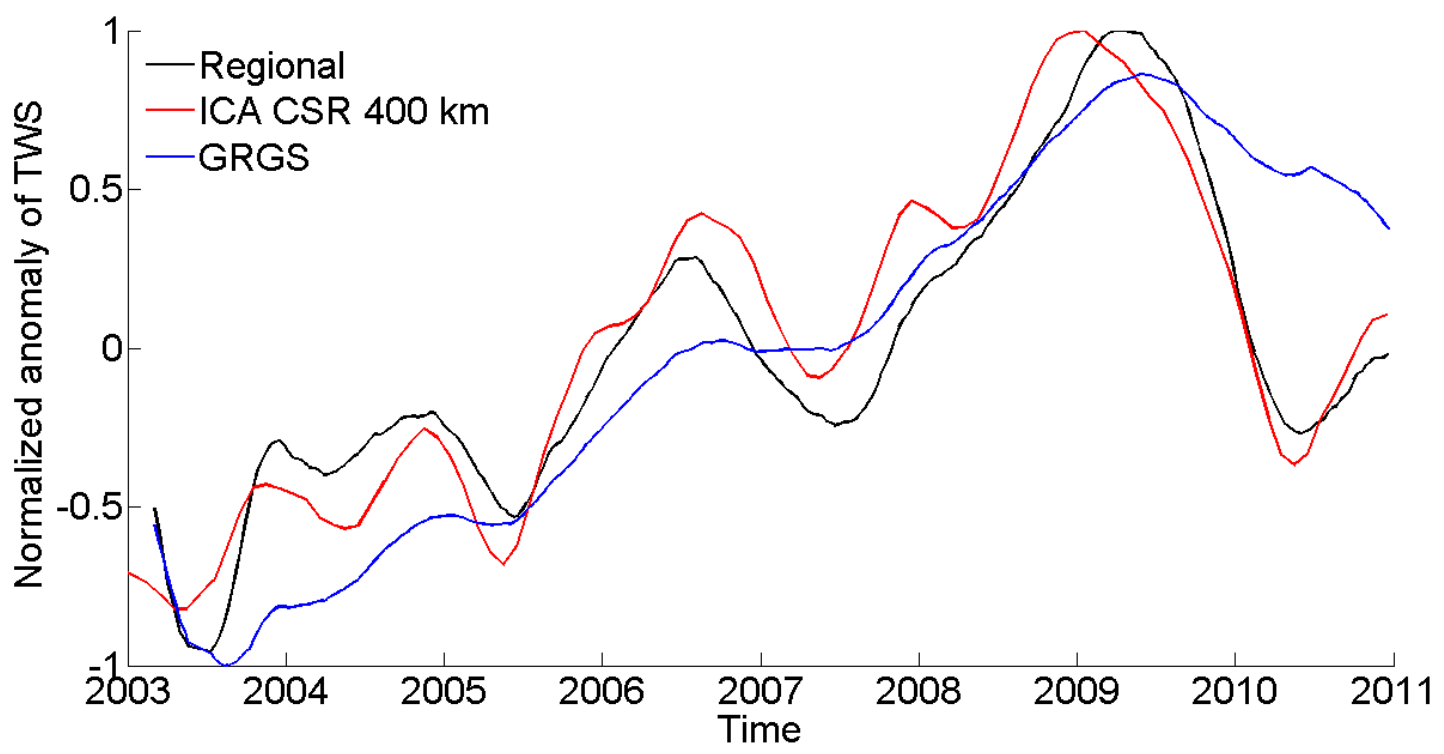

b)

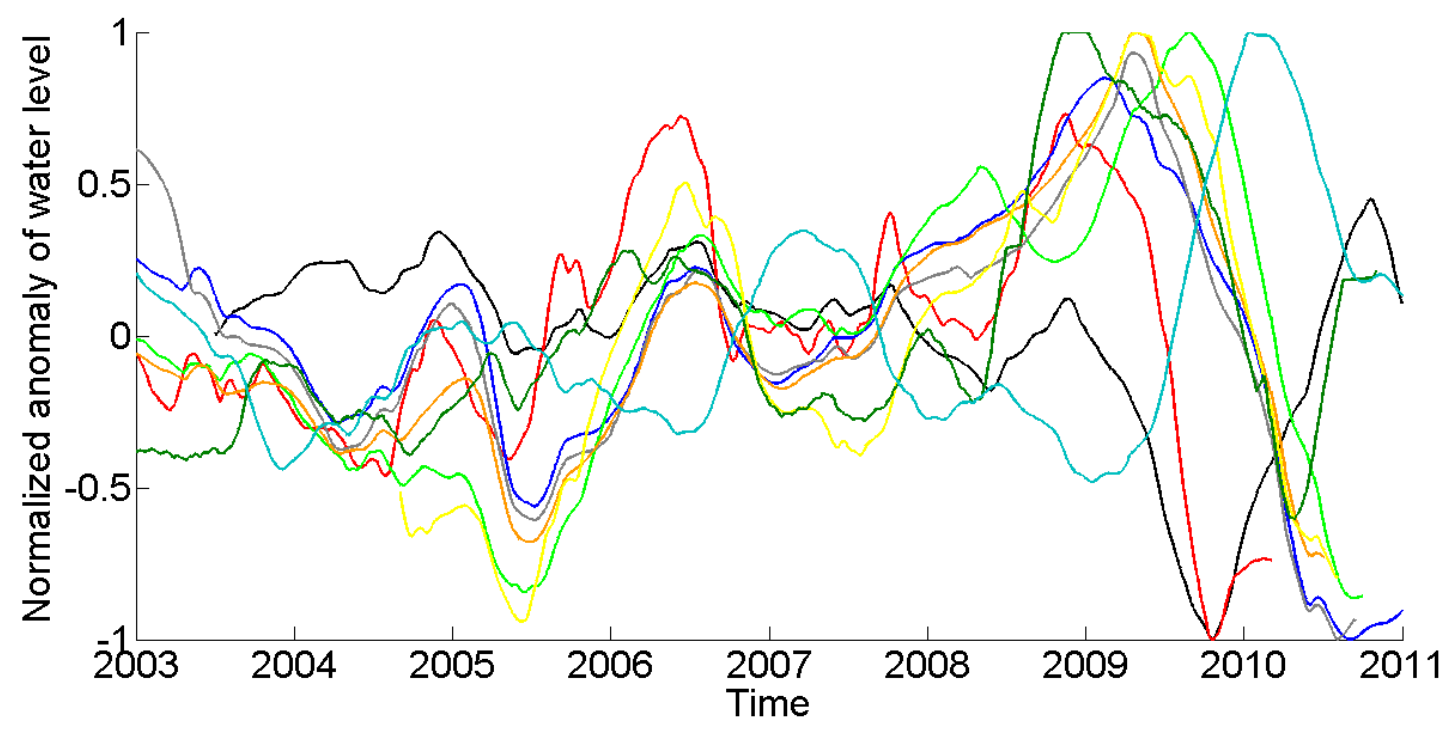

- Ciudad Bolivar

- Serrinha

- Manaus

- Fazenda Vista Alegre

- Jatuarana

- Obidos

Itaituba

Porto de Moz

Batallon 601

Figure 3 : a) Temporal component of the $1^{\text {st }}$ PCA mode of TWS for Regional (black), ICA-CSR (red), and GRGS (blue) solutions over 2003-2010. b) Time variations of normalized water levels correlated with the $1^{\text {st }}$ PCA mode: Ciudad Bolivar (black), Serrinha (red), Manaus (blue), Fazenda Vista Alegre (light green), Jatuarana (grey), Obidos (orange), Itaituba (yellow), Porto de Moz (dark green), Batallon 601 (light blue). 
a)

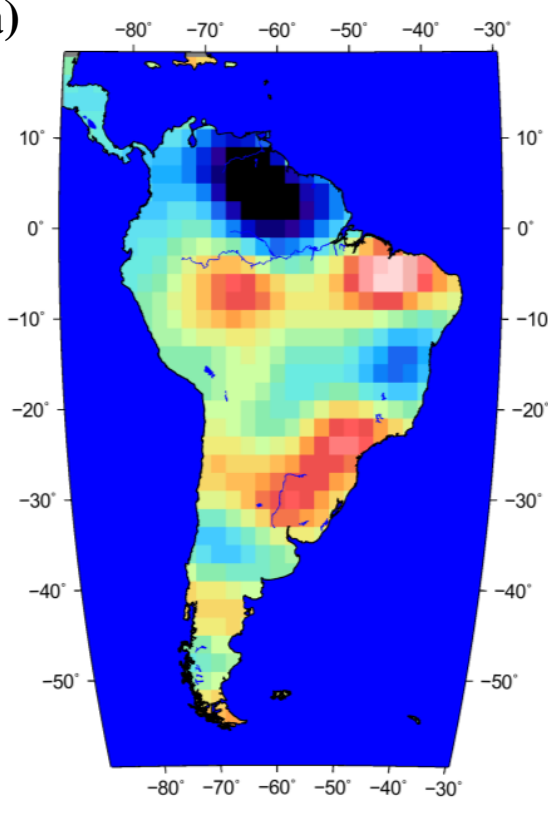

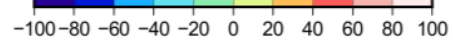

Equivalent-water height $(\mathrm{mm})$

c)

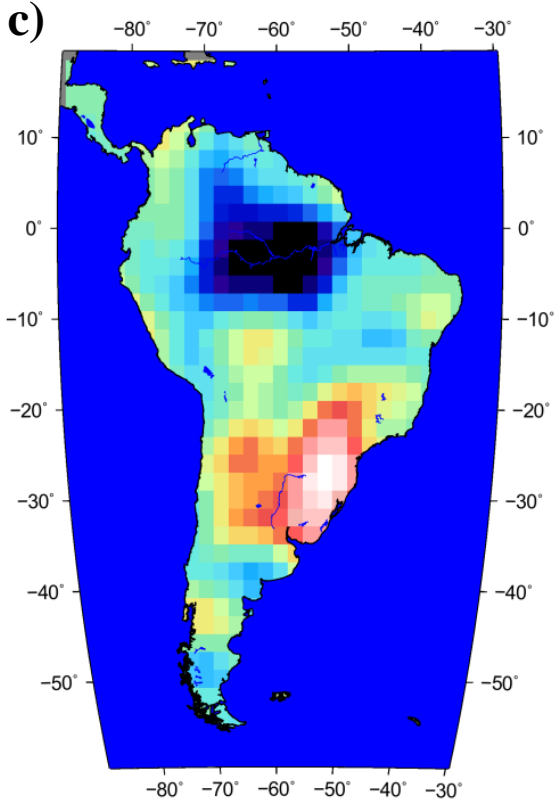

$-100-80-60-40-20 \quad 0 \quad 20 \quad 40 \quad 60 \quad 80100$

Equivalent-water height $(\mathrm{mm})$ b)

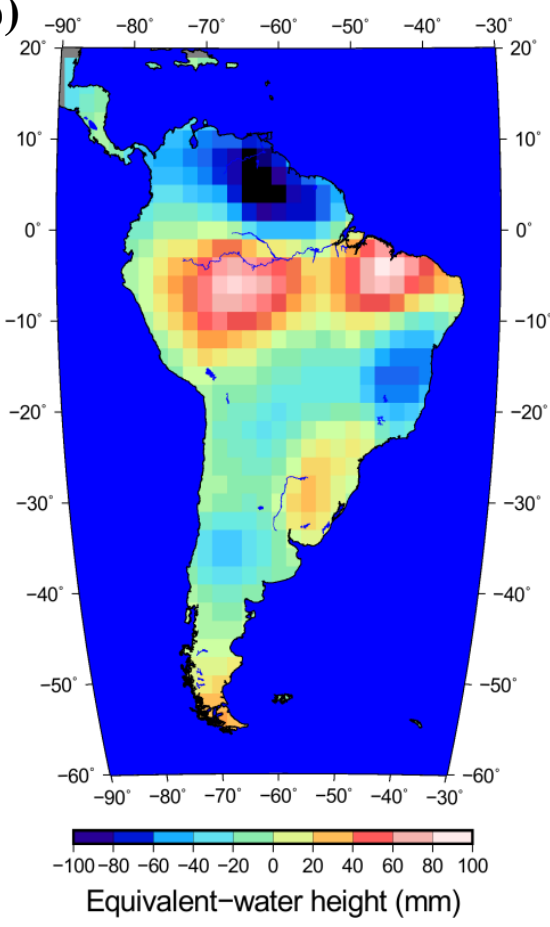

d)

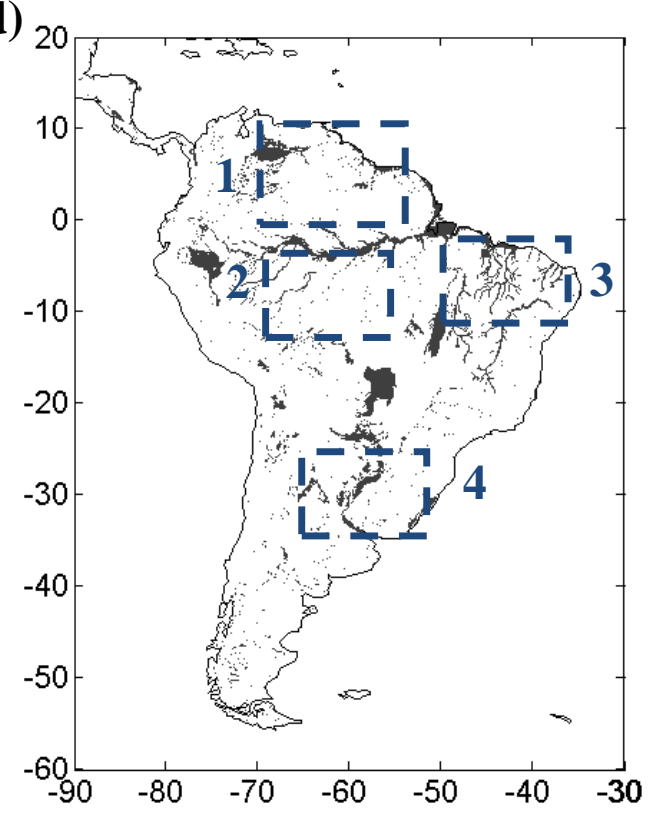

Figure 4: Spatial component of the $2^{\text {nd }}$ PCA mode of TWS for a) Regional $\left.\left(\sigma^{2}=0.2\right), b\right)$ ICA$\operatorname{CSR}\left(\sigma^{2}=0.15\right)$, and c) GRGS $\left(\sigma^{2}=0.14\right)$ solutions over 2003-2010. d) GLWD map of surface water over South America. In the dashed blue rectangles, regions of maximum or minimum of TWS signal: 1 - Orinoco and the Negro basins, 2 - the southern bank of the Solimões, 3 - the region covered with Pindare and Parnacaiba basins, 4 - the downstream part and the delta of La Plata basin. 
a)

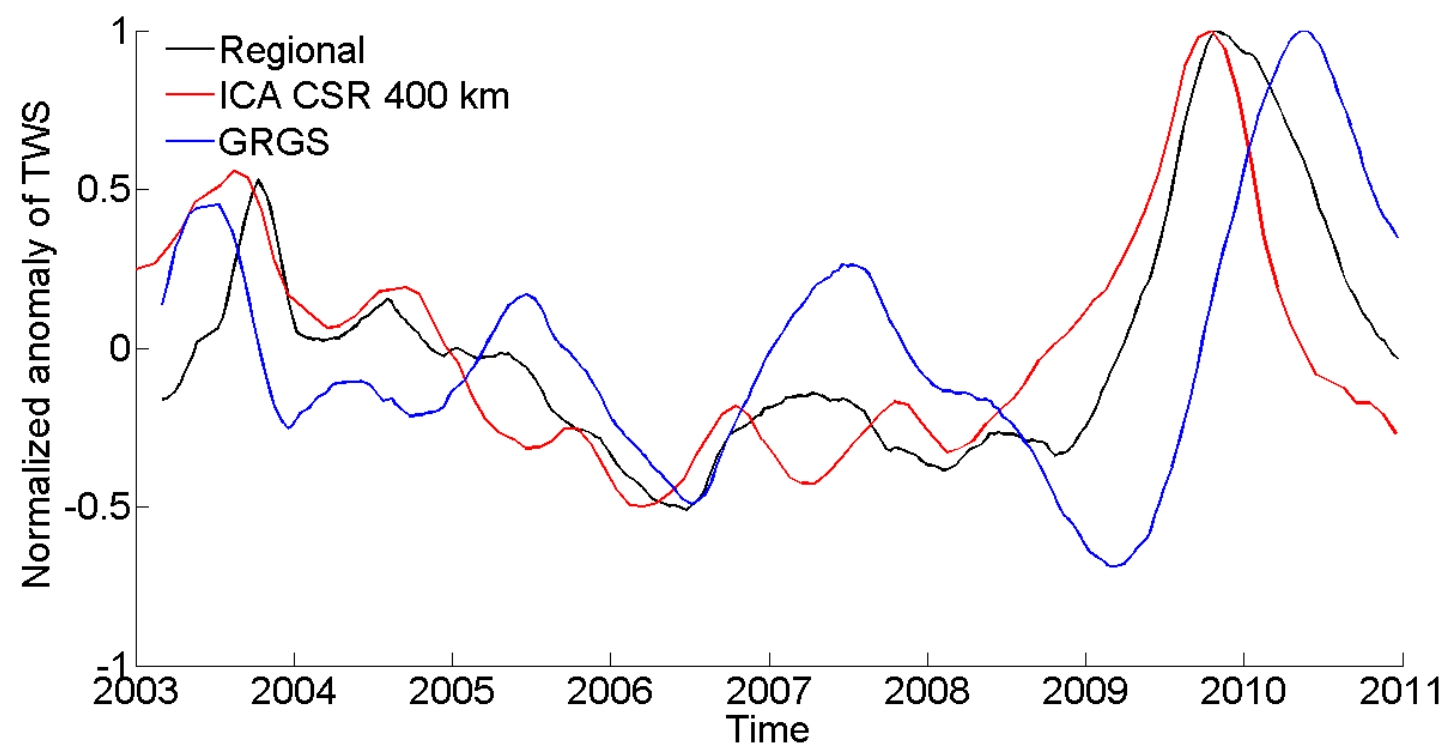

b)

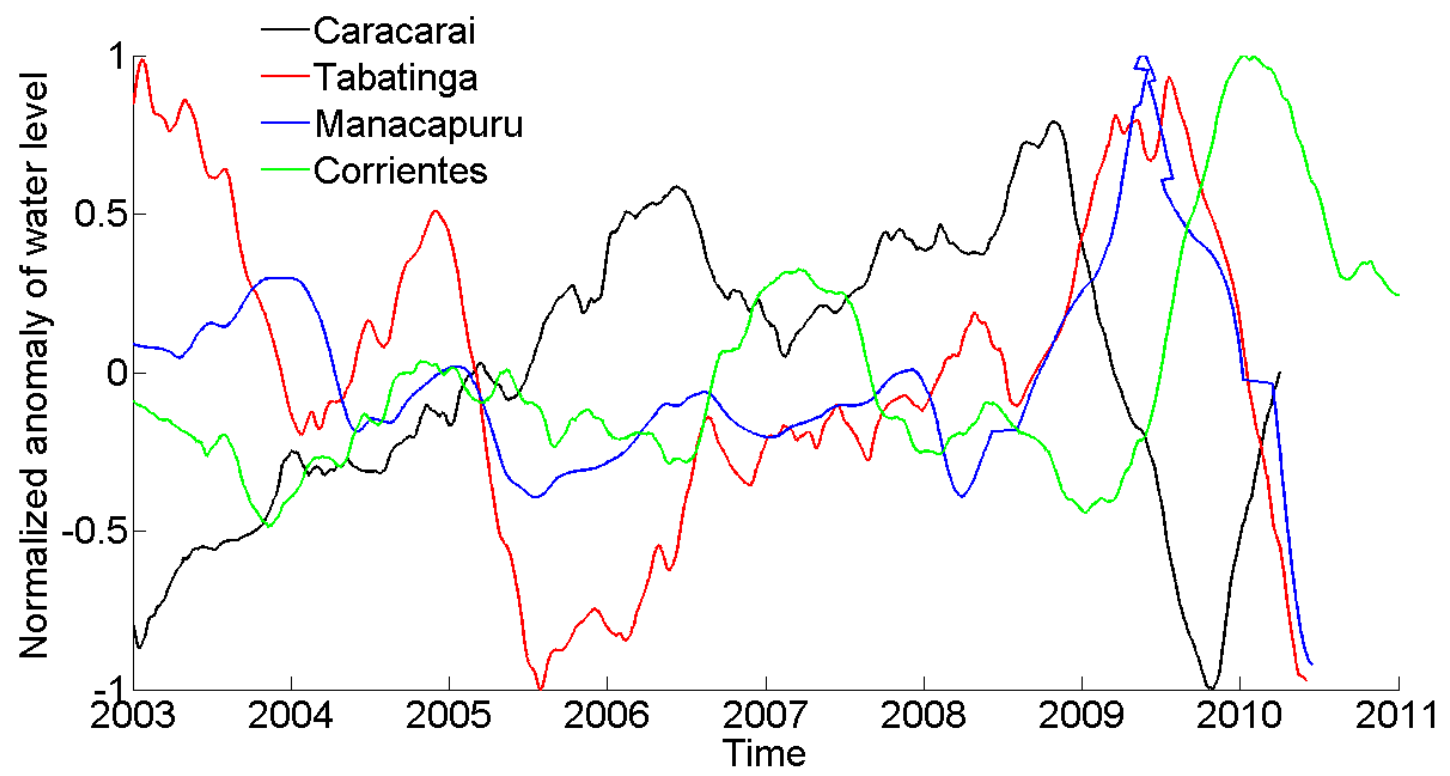

Figure $5:$ a) Temporal component of the $2{ }^{\text {nd }}$ PCA mode of TWS for Regional (black), ICA-CSR (red), and GRGS (blue) solutions over 2003-2010. b) Time variations of normalized water levels correlated with the $2^{\text {nd }}$ PCA mode: Caracarai (black), Tabatinga (red), Manacapuru (blue), Corrientes (green). 


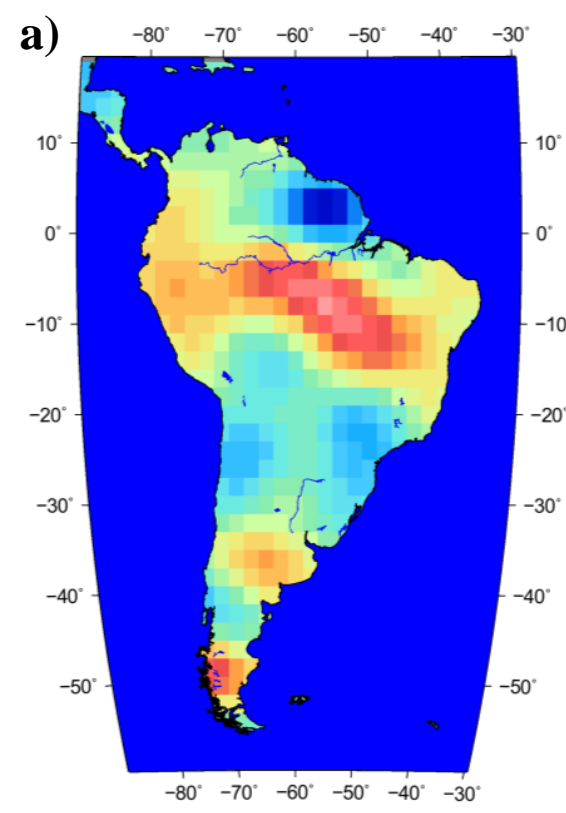

$\begin{array}{llllll}-80^{\circ} & -70^{\circ} & -60^{\circ} & -50^{\circ} & -40^{\circ} & -30^{\circ}\end{array}$

$-100-80-60-40-20 \quad 0 \quad 20 \quad 40 \quad 60 \quad 80 \quad 100$ Equivalent-water height $(\mathrm{mm})$

c)

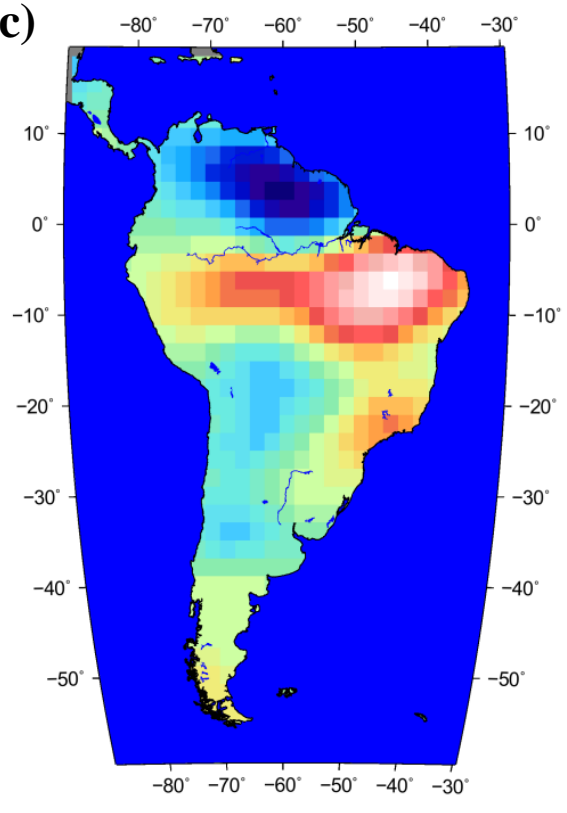

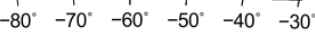

$-100-80-60-40-20 \quad 0 \quad 20 \quad 40 \quad 60 \quad 80 \quad 100$

Equivalent-water height ( $\mathrm{mm})$ b) $20^{\circ}-90^{\circ} \quad-80^{\circ} \quad-70^{\circ} \quad-60^{\circ} \quad-50^{\circ} \quad-40^{\circ} \quad-30^{\circ}$

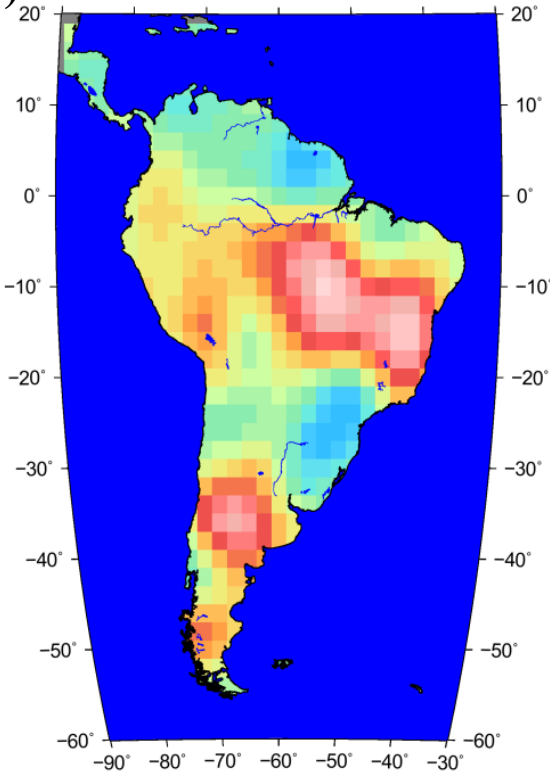

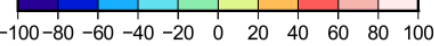

Equivalent-water height $(\mathrm{mm})$

d)

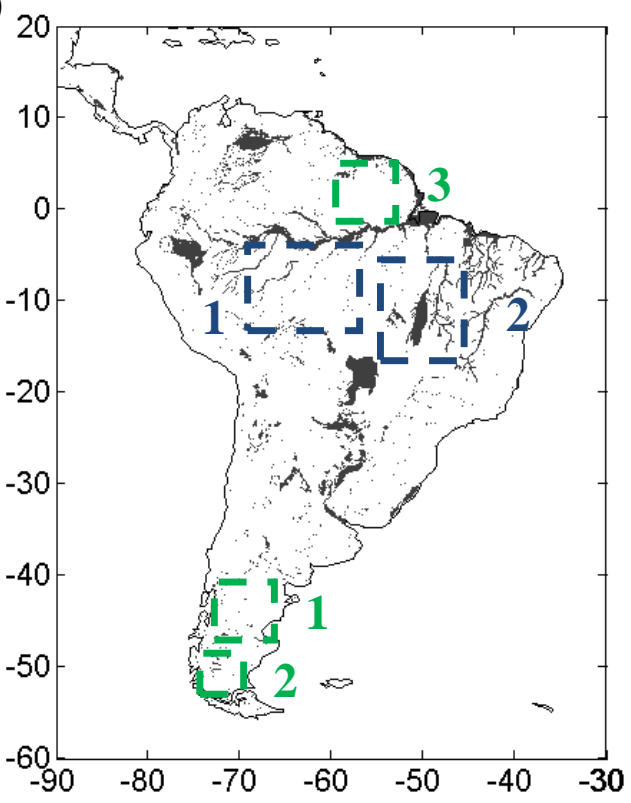

Figure 6 : Spatial component of the $3^{\text {rd }}$ PCA mode of TWS for a) Regional $\left.\left(\sigma^{2}=0.13\right), b\right)$ ICACSR $\left(\sigma^{2}=0.14\right)$, and c) GRGS ( $\left.\sigma^{2}=0.1\right)$ solutions over 2003-2010. d) GLWD map of surface water over South America. In the dashed blue rectangles, regions of maximum or minimum of TWS signal: 1 - southern bank of the Solimões and the central corridor of the Amazon until the junction with the Tapajos river 2 - upstream part of the Tocantins. In the dashed green rectangles, secondary extrema of TWS: 1 - Negro basin, 2 - Patagonia Icefield and Deseado basin, 3 Essequibo (Guyana), Suriname (Suriname), Oyapok and Maroni (French Guiana) basins. 


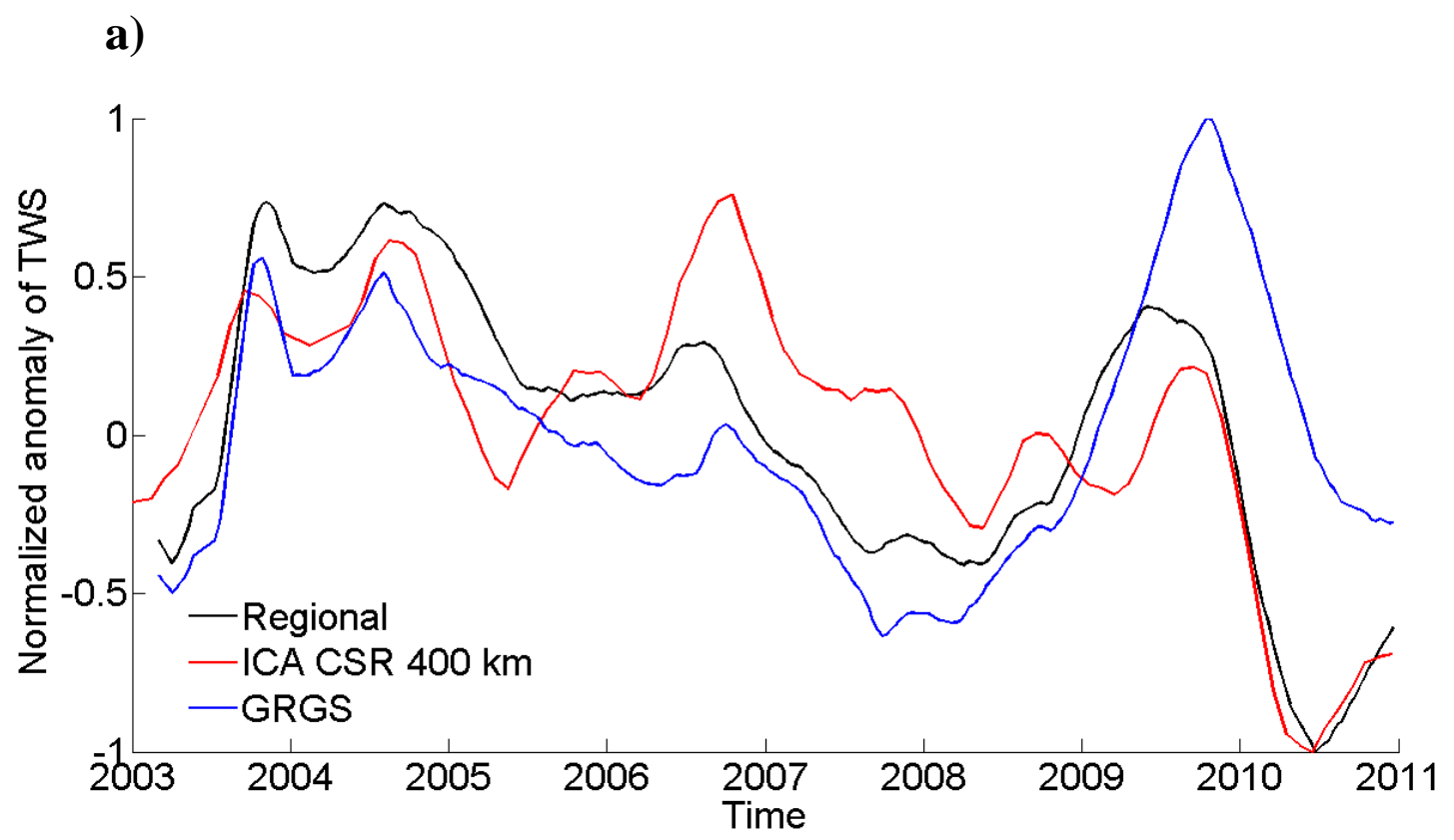

b)

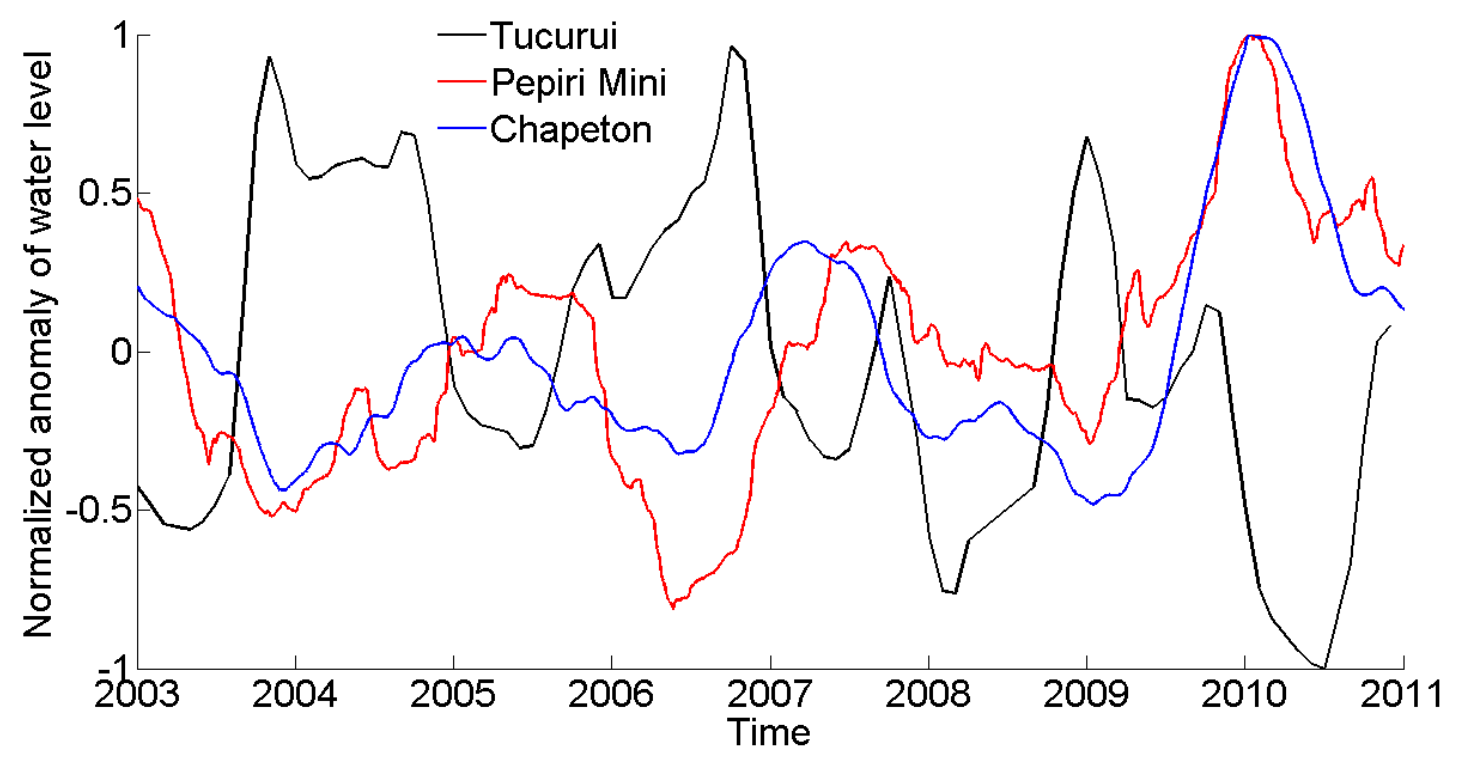

Figure $7:$ a) Temporal component of the $3^{\text {rd }}$ PCA mode of TWS for Regional (black), ICA-CSR (red), and GRGS (blue) solutions over 2003-2010. b) Time variations of normalized water levels correlated with the $3^{\text {rd }}$ PCA mode: Tucurui (black), Pepiri Mini (red), Chapeton (blue). 

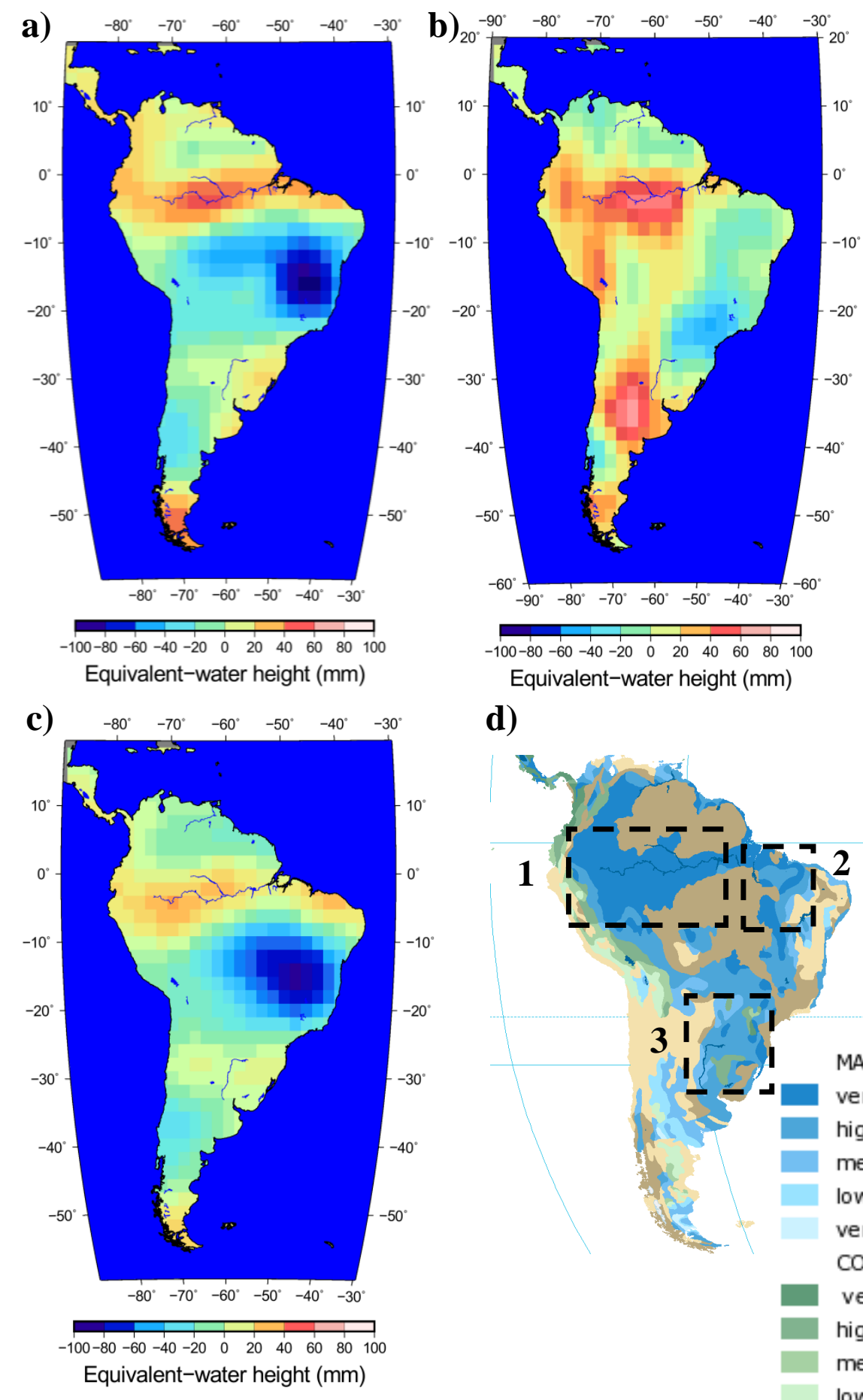

d)

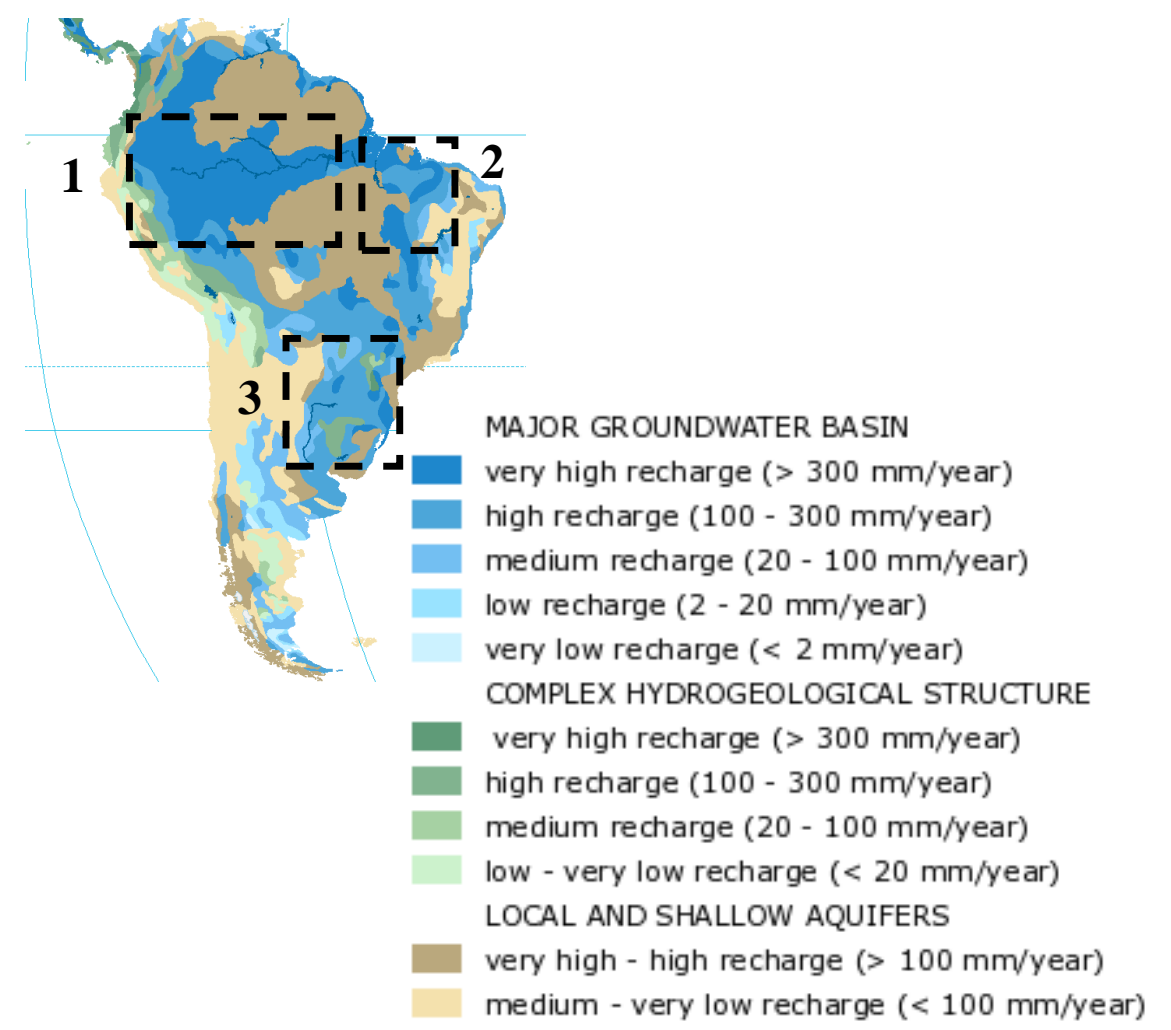

Figure 8 : Spatial component of the $4^{\text {th }}$ PCA mode of TWS for a) Regional $\left(\sigma^{2}=0.11\right)$, b) ICA$\operatorname{CSR}\left(\sigma^{2}=0.1\right)$, and c) GRGS $\left(\sigma^{2}=0.08\right)$ solutions over 2003-2010. d) WHYMAP map of groundwater recharge over South America. In the dashed black rectangles, regions of maximum or minimum of TWS signal: 1 - Amazonas, 2 - Maranhão, 3 - Guarani aquifer systems (adapted from Margat (2007)). 


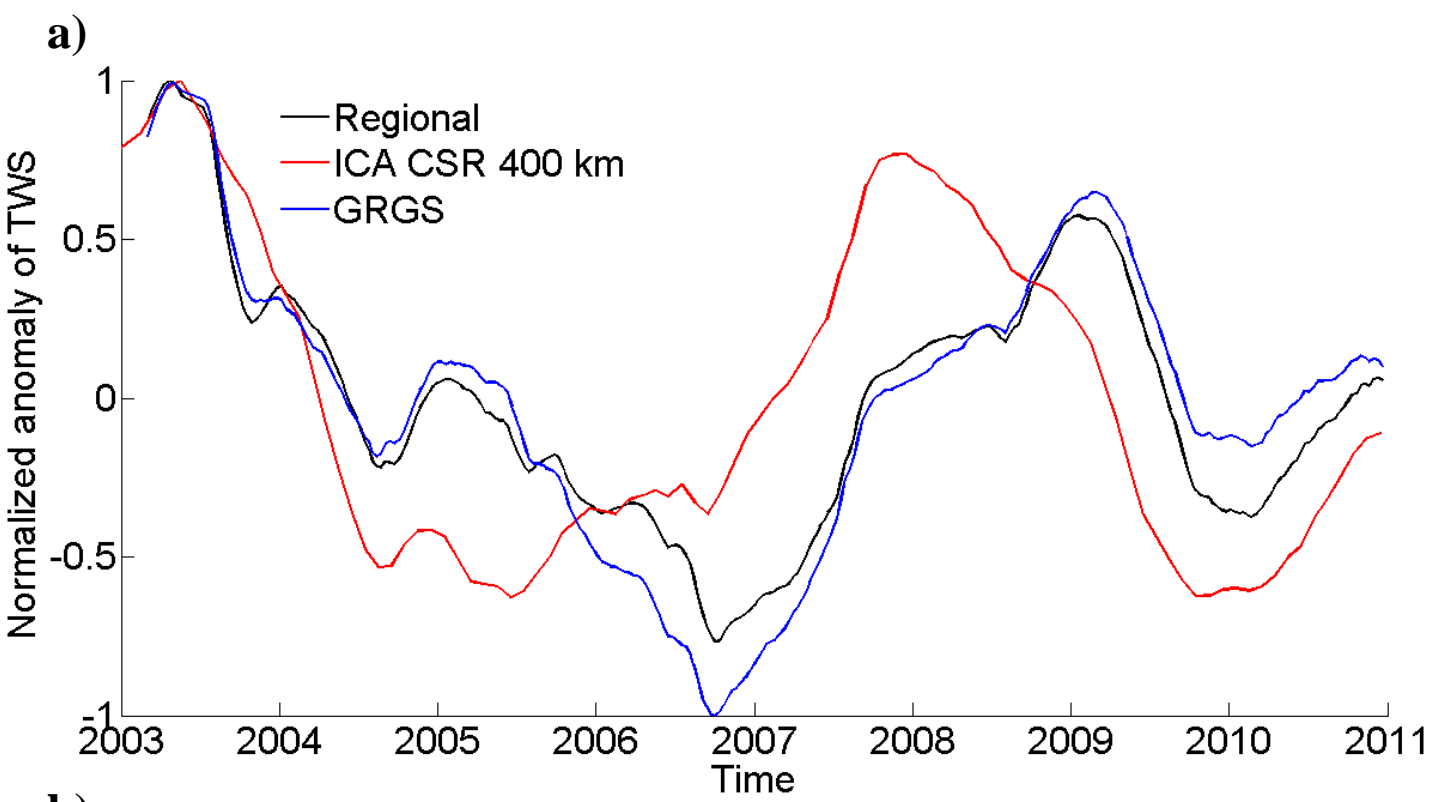

b)

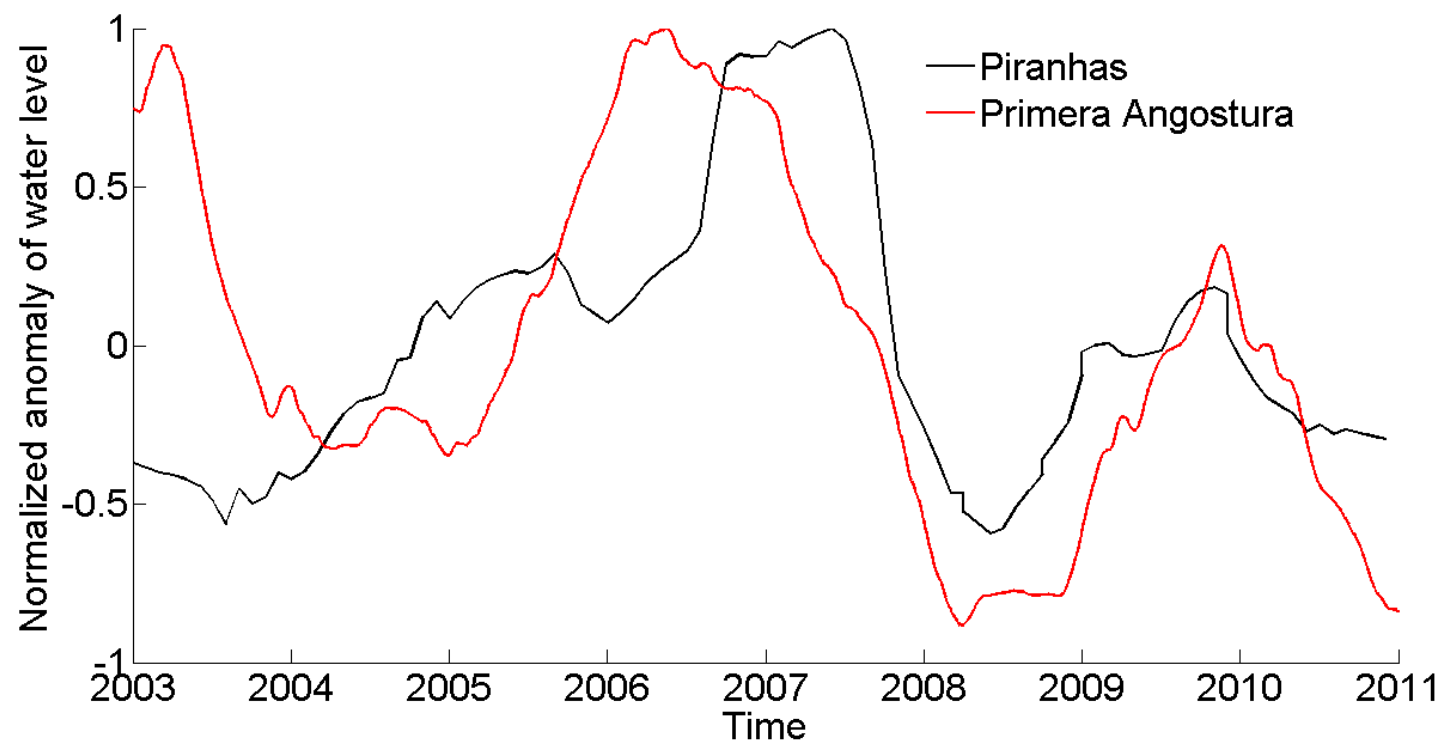

Figure 9 : a) Temporal component of the $4{ }^{\text {th }}$ PCA mode of TWS for Regional (black), ICA-CSR (red), and GRGS (blue) solutions over 2003-2010. b) Time variations of normalized water levels correlated with the $4^{\text {th }}$ PCA mode: Piranhas (black), Primera Angostura (red). 
a)

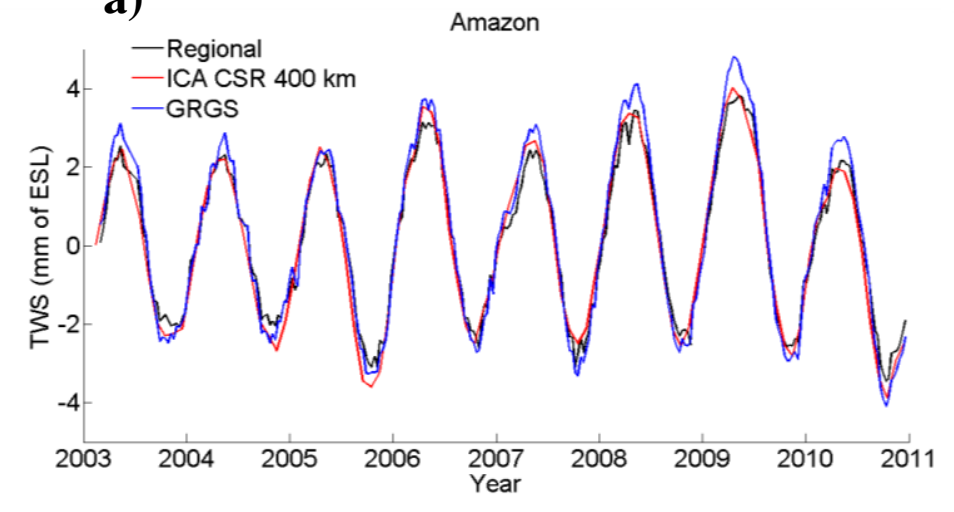

c)

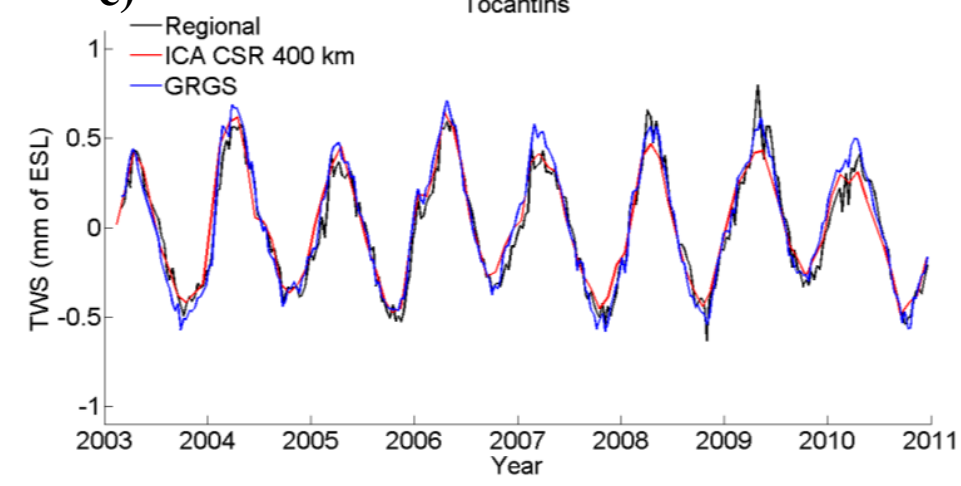

b)

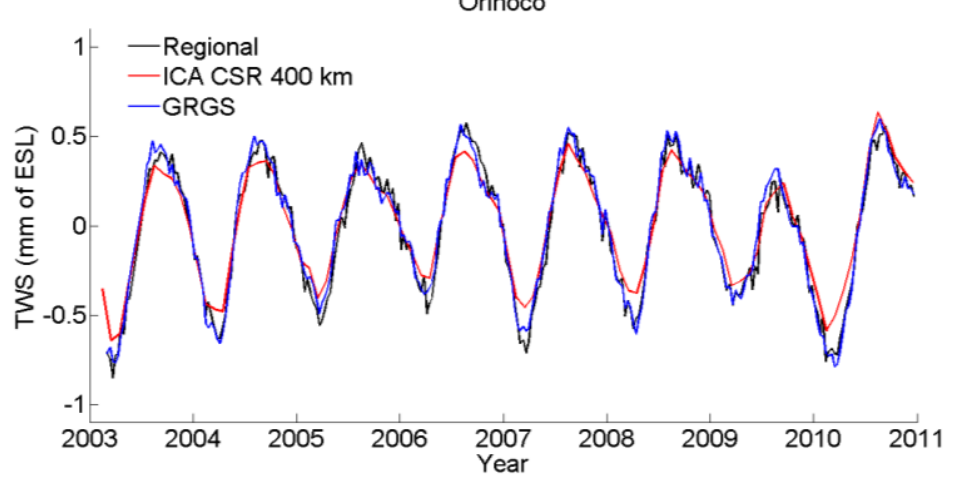

d)

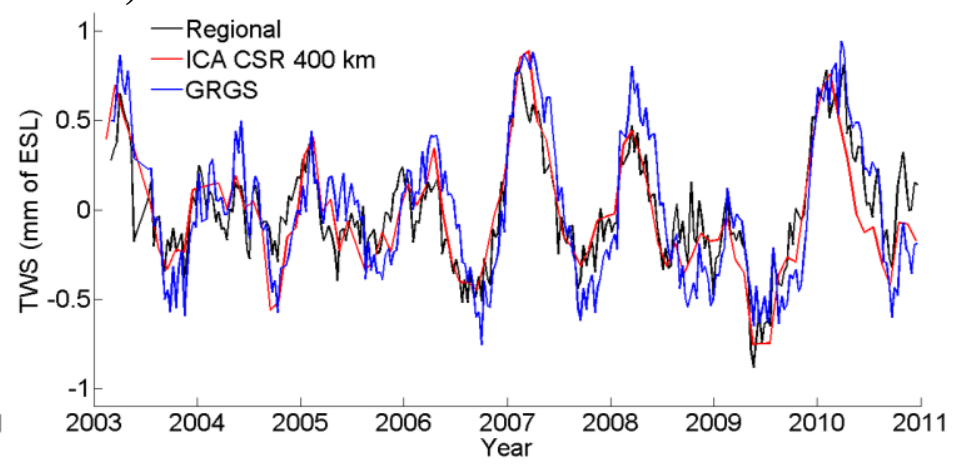

Figure 10 : Time-series of GRACE-based TWS over 2003-2010 from Regional (black), ICA CSR $400 \mathrm{~km}$ (red), GRGS (blue) expressed in mm of ESL for the a) Amazon, b) Orinoco, c) Tocantins, and d) La Plata basins. 

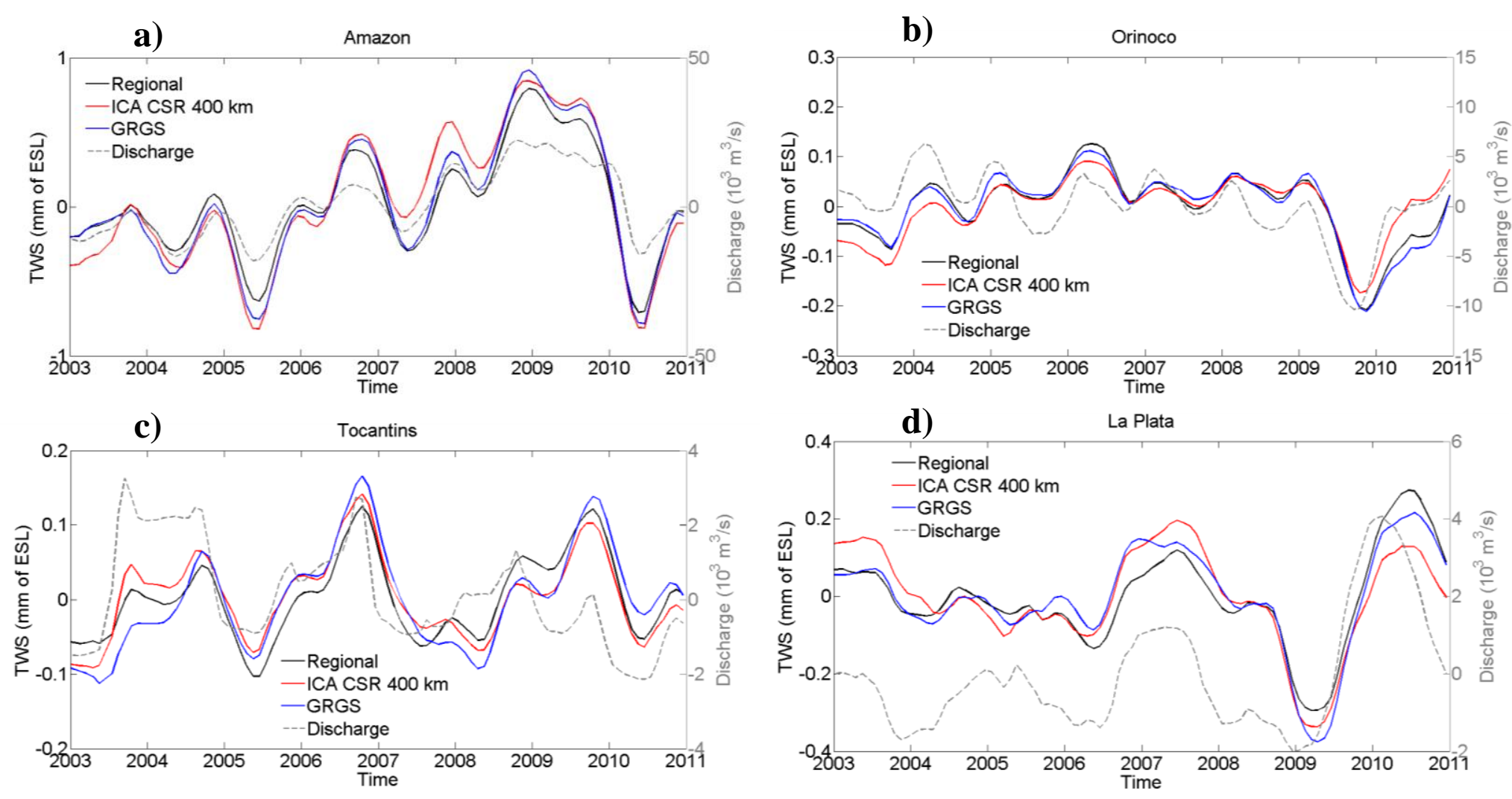

Figure 11 : Time-series of GRACE-based interannual TWS over 2003-2010 from Regional (black), ICA CSR $400 \mathrm{~km}$ (red), GRGS (blue) expressed in mm of ESL and of interannual discharge (grey) for the a) Amazon, b) Orinoco, c) Tocantins, and d) La Plata basins. 